University of Wollongong

Research Online

Faculty of Engineering and Information

Faculty of Engineering and Information

Sciences - Papers: Part B

Sciences

2020

Development and evaluation of a versatile semi-active suspension system for high-speed railway vehicles

Tianhe Jin

University of Wollongong, Beijing Jiaotong University

Zhiming Liu

Beijing Jiaotong University

Shuaishuai Sun

University of Wollongong, ssun@uow.edu.au

Zunsong Ren

Beijing Jiaotong University

Lei Deng

University of Wollongong, Id530@uowmail.edu.au

See next page for additional authors

Follow this and additional works at: https://ro.uow.edu.au/eispapers1

Part of the Engineering Commons, and the Science and Technology Studies Commons

Research Online is the open access institutional repository for the University of Wollongong. For further information contact the UOW Library: research-pubs@uow.edu.au 


\title{
Development and evaluation of a versatile semi-active suspension system for high-speed railway vehicles
}

\begin{abstract}
With the increase in speed of high-speed trains, their vibration will become fiercer and fiercer, especially when the lateral resonance of the car body occurs. This paper develops a versatile semi-active suspension system with variable stiffness (VS) magnetorheological elastomer (MRE) isolators and variable damping (VD) magnetorheological (MR) dampers for high-speed trains, aiming to improve ride comfort by avoiding car body resonance and dissipating vibration energy. As the first step, a multifunction VSVD semi-active suspension system for high-speed railway vehicles was designed and prototyped, including four VS-MRE isolators and two VD-MR dampers. After that, a scaled train model, composing of a car body and a secondary lateral suspension system was designed and built to evaluate the performance of the new VSVD suspension system; a control strategy based on short-time Fourier transform (STFT) and sky-hook was proposed to control the new suspension system. Two different excitations, harmonic excitation and random excitation, were applied to evaluate the train's VSVD suspension. As a comparison, four alternative suspension systems, including passive-off suspension, passive-on suspension, pure VS suspension, and pure VD suspension were also evaluated. The evaluation results verified that the VSVD suspension of the train can avoid lateral resonance of car body and dissipate the vibration energy efficiently. The comparison verified that the VSVD suspension system outperforms the passive-off suspension, passive-on suspension, pure VS suspension, and pure VD suspension.

\section{Disciplines}

Engineering | Science and Technology Studies

\section{Publication Details}

Jin, T., Liu, Z., Sun, S., Ren, Z., Deng, L., Yang, B., Christie, M. Daniel. \& Li, W. (2020). Development and evaluation of a versatile semi-active suspension system for high-speed railway vehicles. Mechanical Systems and Signal Processing, 135 106338-1-106338-17.

\section{Authors}

Tianhe Jin, Zhiming Liu, Shuaishuai Sun, Zunsong Ren, Lei Deng, Bo Yang, Matthew Christie, and Weihua $\mathrm{Li}$
\end{abstract}




\title{
Development and Evaluation of a Versatile Semi-Active Suspension System for High-Speed Railway Vehicles
}

\author{
Tianhe Jin ${ }^{1,2}$, Zhiming liu ${ }^{1}$, Shuaishuai Sun², Zunsong Ren $^{1}$, Lei Deng ${ }^{2}$, Bo Yang ${ }^{2,3}$, \\ Matthew Daniel Christie ${ }^{2}$ and Weihua $\mathrm{Li}^{2}$ \\ ${ }^{1}$ School of Mechanical, Electronic and Control Engineering, Beijing Jiaotong University, Beijing \\ 100044, China \\ ${ }^{2}$ School of Mechanical, Materials, Mechatronic and Biomedical Engineering, University of \\ Wollongong, NSW 2522, Australia \\ ${ }^{3}$ School of Mechanical Engineering and Automation, Northeastern University, Shenyang 110819, \\ China \\ E-mail: Tianhe Jin: 16116364@bjtu.edu.cn and Shuaishuai Sun: ssun@uow.edu.au.
}

\begin{abstract}
With the increase in speed of high-speed trains, their vibration will become fiercer and fiercer, especially when the lateral resonance of the car body occurs. This paper develops a versatile semiactive suspension system with variable stiffness (VS) magnetorheological elastomer (MRE) isolators and variable damping (VD) magnetorheological (MR) dampers for high-speed trains, aiming to improve ride comfort by avoiding car body resonance and dissipating vibration energy. As the first step, a multifunction VSVD semi-active suspension system for high-speed railway vehicle was designed and prototyped, including four VS-MRE isolators and two VD-MR dampers. After that, a scaled train model, composing of a car body and a secondary lateral suspension system was designed and built to evaluate the performance of the new VSVD suspension system; a control strategy based on short-time Fourier transform (STFT) and sky-hook was proposed to control the new suspension system. Two different excitations, harmonic excitation and random excitation, were applied to evaluate the train's VSVD suspension. As a comparison, four alternative suspension systems, including passive-off suspension, passive-on suspension, pure VS suspension, and pure VD suspension were also evaluated. The evaluation results verified that the VSVD suspension of the train can avoid lateral resonance of car body and dissipate the vibration energy efficiently. The comparison verified that the VSVD suspension system outperforms the passive-off suspension, passive-on suspension, pure VS suspension, and pure VD suspension.
\end{abstract}

Keywords: high-speed train; vibration control; variable stiffness and variable damping; magnetorheological technology

\section{Introduction}

The development and advancement of high-speed trains have been playing a vital role in promoting economic development in various countries. However, as the speed of high-speed trains increases, the vibrations of their car bodies significantly increase and the ride comfort and running safety of the train reduces sharply $[1,2]$. Therefore, suppressing the car body vibration is essential for improving the operational safety and ride comfort of the railway vehicle. 
The traditional method of suppressing the vibration of a train is to adopt a passive suspension system, which has been studied by many scholars [3-6]. Specifically, Chi et al. [3] studied the influence of train's suspension parameters on its running performance. It was found that increasing the lateral damping and reducing the lateral stiffness of the secondary suspension appropriately are beneficial to improve the lateral stability of high-speed trains. Younesian et al. [4] optimized the damping of the secondary suspension of a high-speed train and proposed an optimal suspension system suitable for high-speed train based on frequency domain spectrum analysis. Qin et al. [5] studied the effect of the stiffness and damping of the secondary lateral suspension on the train's critical speed and wheel-rail wear numerically and optimized the stiffness and damping parameters of the passive suspension system. Jin et al. [6] also analyzed the influence of the lateral and longitudinal damping of the secondary suspension on the dynamic performance of a railway vehicle, and then optimized the lateral damping coefficient of the secondary suspension of a train. The above research focuses on passive suspension systems; however, the parameters of these systems cannot be adjusted in real time according to different operation speeds, different track irregularities, and different loading conditions because the parameters of the passive suspension system are fixed. In order to overcome the limitations of passive suspension, researchers have been investigating adaptive suspension system to improve the vibration reduction performance of high-speed trains. For instance, active suspension systems have been applied on high-speed train suspension systems [7-9]. In particular, Maruyama et al. [7] proposed an active suspension system to improve the ride comfort of railway vehicles, and conducted experimental evaluation using a Series 500 Shinkansen railway vehicles of Japan. The results show that the active suspension system can ensure the ride comfort of railway vehicles at high speed. Orvnas [8] and Qazizadeh [9] applied active control to the secondary lateral suspension system of rail vehicles and the testing results show that active suspension can provide better ride comfort than passive suspension. Although the active suspension can improve the running performance of the rail vehicle, the energy consumption and hardware cost of active suspension system are high. Moreover, active control has high possibility to cause instable problem to the train system, which also limits its practical application in high speed trains.

Semi-active suspension, as another typical adaptive suspension system, has gained more and more attention due to its lower energy consumption and controllable parameters that can be adjusted in real time [10-16]. For example, variable orifice dampers and smart-fluid-based dampers have been developed to suppress the vibration of high-speed railway vehicles [17-19]. The semi-active suspension based on the variable orifice dampers realize damping variation by controlling the mechanical valve to change the orifice size, comparatively, the smart-fluid-based dampers adjust damping by controlling the viscosity of the fluids. Comparing with orifice changing damper, these adaptive dampers have advantages of less mechanical parts, improved stability, lower maintenance costs, and quicker response [19]. Electrorheological (ER) fluids and magnetorheological (MR) fluids are two typical fluids which have been widely used to develop adaptive dampers [20]. They can change from a free-flowing fluid state to a semi-solid state in milliseconds when electrical or magnetic fields are applied to them. Since the ER fluid is energized by applying an electric field of up to $8 \mathrm{kV} / \mathrm{mm}$, the safety of the ER semi-active suspension has been a big concern for its practical application [21, 22]. On the contrary, MR fluids only require a small voltage to control its viscosity and have been widely used to develop variable damping suspension systems for high-speed trains [23-31]. As an example, Wang et al. [24, 25] applied MR dampers to build semi-active secondary lateral suspension for train to improve its ride comfort. A 17-Degree-of-Freedom (DOF) rail vehicle 
model was also built to evaluate the performance of the MR suspension numerically. Zong et al. [26] built a Ho control strategy to control the MR suspension system for high speed train to improve its dynamic performance. Sun et al. [27] built four MR dampers for high speed train and experimentally verified that MR suspension system is able to improve the critical speed of the railway vehicle. Shin et al. [28] also conducted research on the application of MR damper on highspeed trains and evaluated the ride comfort and lateral stability of the railway vehicle which is installed with MR dampers.

Although the controllable-damping suspension system can greatly improve the ride comfort and operational stability of railway vehicles, the stiffness of the secondary lateral suspension of the railway vehicles cannot be adjusted, which fixes the resonance frequency of the vehicle body in lateral direction. According to the studies of Chi et al. [32] and H. Claus et al. [33], the track excitation frequency increases with the increase of the vehicle speed, which means the excitation frequency will be equal to the resonance frequency of high-speed train at certain operation speed. This resonance will induce serious laterally vibration of the car body, which will significantly reduce the ride comfort and safety of the high-speed trains. Therefore, apart from damping controllable suspension, stiffness adjustable suspension system needs to be developed urgently to avoid the lateral resonance of the car body and improve the dynamics performance of the high-speed railway vehicle.

Based on this motivation, this paper develops a versatile VSVD suspension system for high speed trains. This advanced suspension will meet the demanding requirements during different working scenarios by realizing non-resonance control with stiffness controllability and efficient vibration energy dissipation with damping controllability. The structure of this paper is as follows. In Section 2, the detailed design, working principle of the multifunction VSVD semi-active suspension, VSVD devices and a small scaled high-speed railway vehicle model are presented, along with the testing results of the VS and VD devices. Section 3 proposes a VSVD control strategy and presents the evaluation of multifunction semi-active suspension on a small-scale high-speed railway vehicle under harmonic and random excitation. Lastly, Section 4 concludes this paper.

\section{Design, prototype and testing of the multifunctional semi-active suspension system for high- speed railway vehicle}

This chapter describes the working principle of the proposed multifunctional semi-active suspension system for high-speed railway vehicles, as well as the prototype, simulation, and testing of the corresponding VS isolator and VD dampers.

\subsection{The structure, design and working principle of the multifunctional VSVD semi-active suspension system}

In order to verify the effect of the VSVD suspension system on the high-speed railway vehicle, in this paper a small-scale railway vehicle system is designed and manufactured, as shown in Figure 1. This railway vehicle system mainly consists of a car body, a secondary lateral semi-active suspension system, and two bogies. Considering the maximum vertical support capability of the test bench, the mass of the scaled car body is chosen to be $70 \mathrm{~kg}$. The actual car body mass is $36000 \mathrm{~kg}$; thus the weight ratio of the scaled car body and the actual car body is approximately 1:512. According to the scaling rule used in A. Jaschinski [34] and Y.J. Shin [35], the scale factor of the train size used in this paper is $1: \sqrt[3]{512}=1: 8$. Therefore, other dimensions and parameters of the 
scaled train can be determined by the scaling factor and is given in Table 1. For the VSVD suspension system, both the stiffness and damping are controlled according to different working scenarios. The schematic diagram is shown in Figure 1(a) and (b), where the $y_{c}, y_{b}, k_{y}$ and $c_{y}$ represent the lateral displacement of the car body, the lateral displacement of the bogies, the secondary lateral variable stiffness and the damping, respectively. The secondary lateral semi-active suspension system of the railway vehicle, as shown in Figure 1(c), mainly includes four VS-MRE isolators and two VD-MR dampers. The four MRE isolators are used as the secondary vertical springs to support the weight of the railway vehicle and provide controllable lateral stiffness to the train system. The MRE isolator can replace the air spring in the train's suspension system without large configuration change to the train. The two MR dampers are used as secondary lateral dampers and provide controllable lateral damping to train's suspension. This research focuses on secondary suspension system, and the bogie structure has been simplified as a support plate, as shown in Figure $1(\mathrm{c})$.

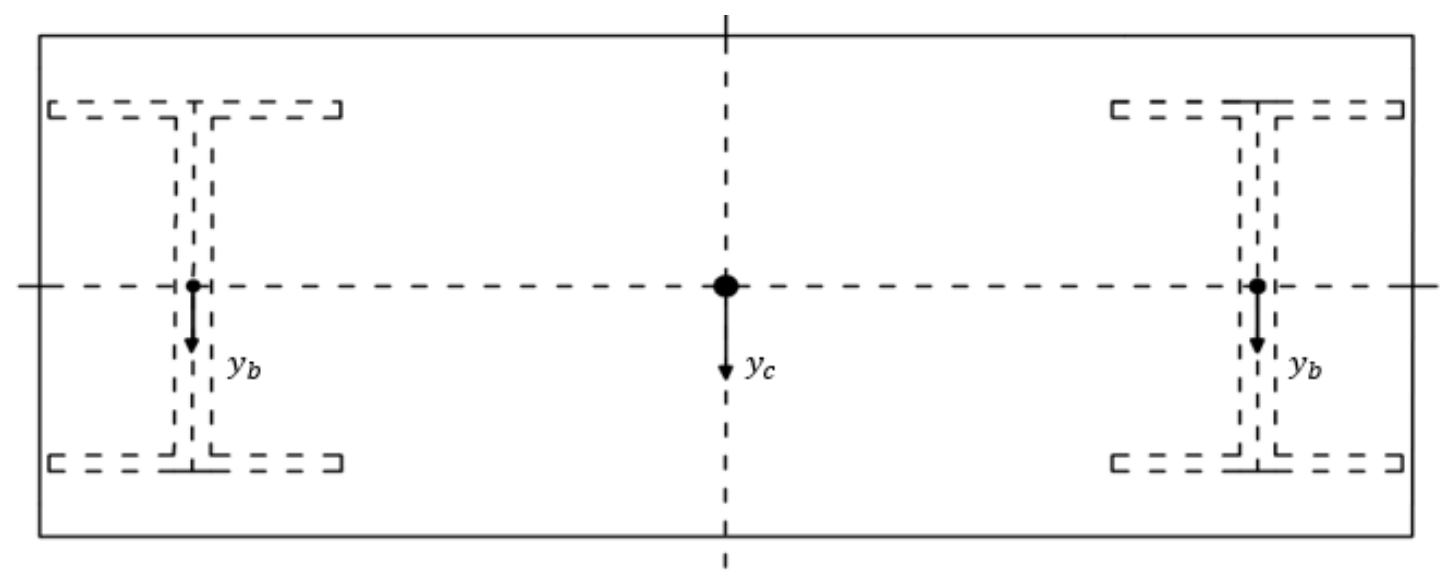

(a) Top view of the railway vehicle model.

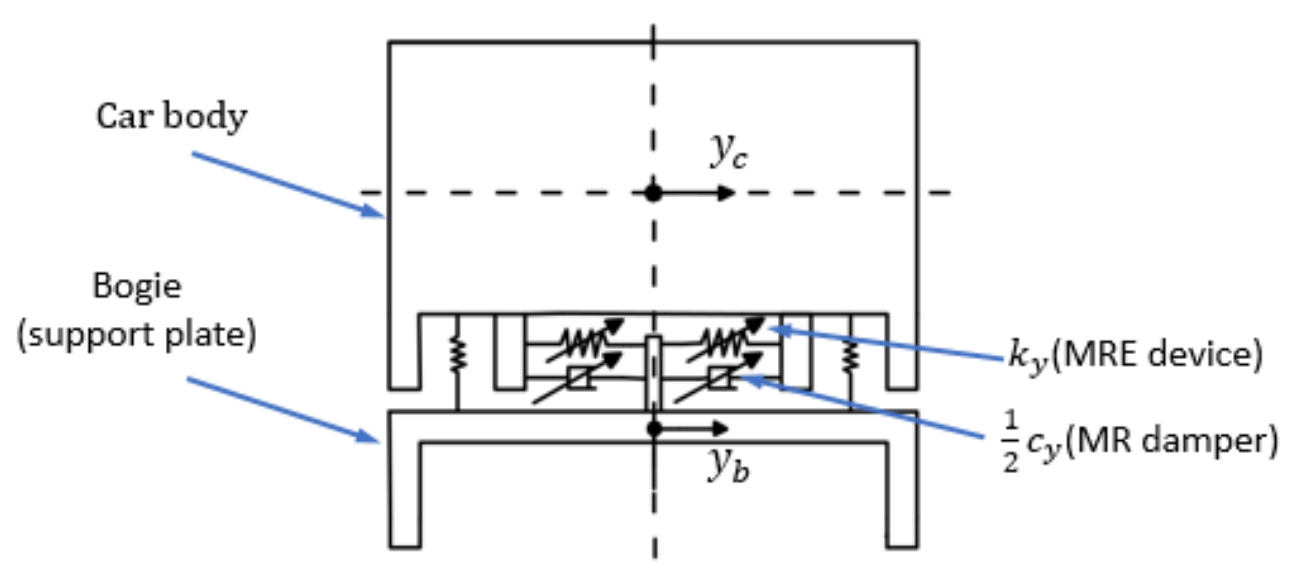

(b) Back view of Rear and Front bogie of the railway vehicle. 


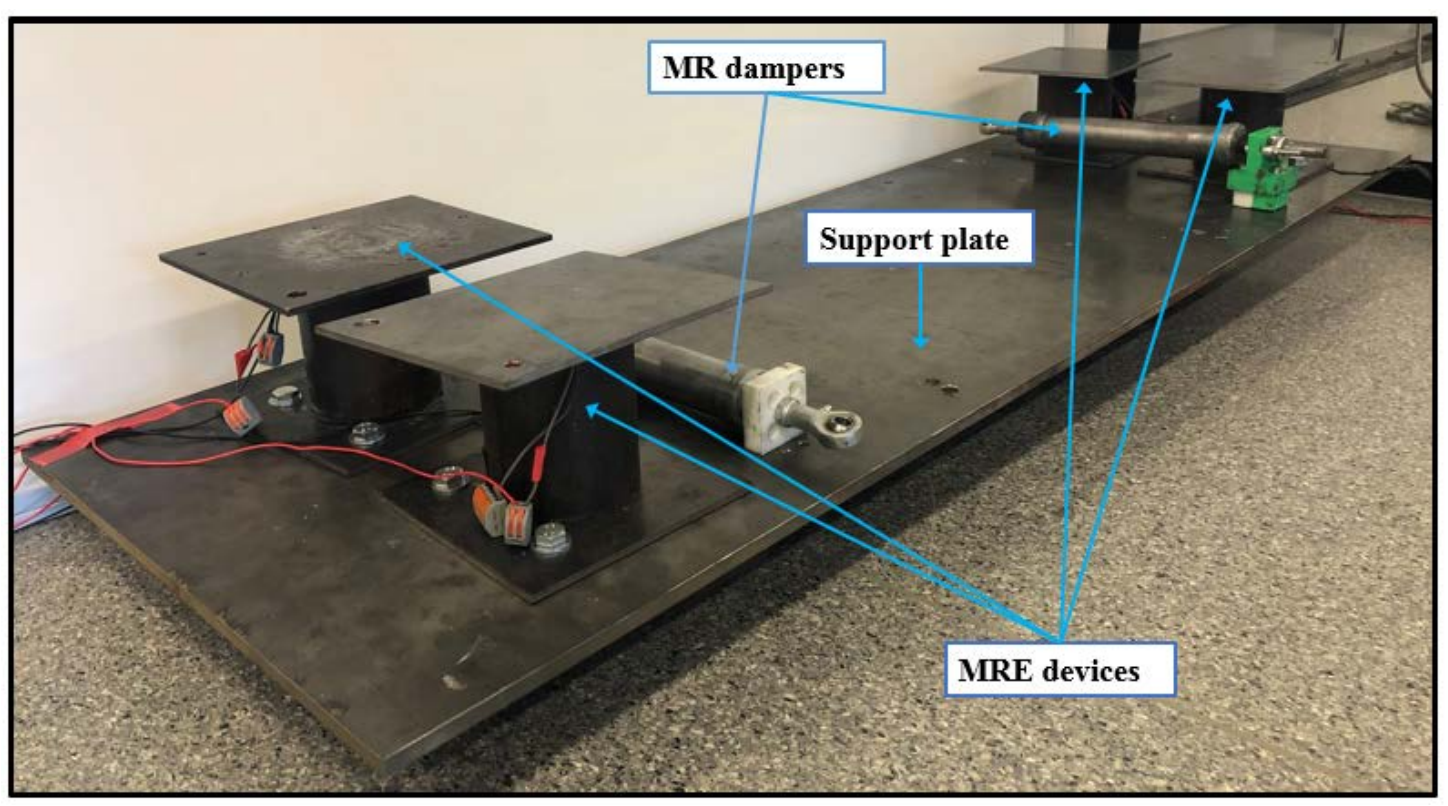

(c) Secondary suspension system of the high-speed railway vehicle.

Figure 1. Structure and prototype of the scaled railway vehicle.

Table 1. Scaling factors and parameter values.

\begin{tabular}{cccc}
\hline Parameters & Full-scale & Scale factor & Small-scale \\
\hline Mass of car body (kg) & 36000 & $\frac{1}{\varphi^{3}}$ & 70 \\
Length of car body frame (m) & 20 & $\frac{1}{\varphi}$ & 1.7 \\
Width of car body frame (m) & 6.25 & $\frac{1}{\varphi}$ & 0.78 \\
\hline
\end{tabular}

For the VSVD semi-active suspension system, all the MR dampers and MRE isolators will be properly controlled to achieve a variable stiffness variable damping suspension system. As a comparison, four alternative suspension systems were also designed and tested, which are detailed as follows:

Case 1: passive-off suspension: passive-off suspension system uses MRE isolators and MR dampers as passive components without applying control strategies to them. In this case, the stiffness and damping of the suspension system are fixed and the currents to the MRE isolators and MR dampers are set to be constant $3 \mathrm{~A}$ and $0 \mathrm{~A}$, respectively.

Case 2: passive-on suspension: passive-on suspension system uses MRE isolators and MR dampers as passive components and the currents to the MRE isolators and MR dampers are set to be constant $3 \mathrm{~A}$ and $2 \mathrm{~A}$, respectively.

Case 3: VS suspension. VS suspension system only applies a control strategy to the MRE isolators while the MR dampers serve as passive components. The VS suspension can only change its stiffness in real time and cannot adjust its damping. In this way, the current of the MRE isolators is controlled while the current of the MR dampers is set to be constant $0 \mathrm{~A}$. 
Case 4: VD suspension. VD suspension is a suspension system that uses the MR dampers as controllable components while the MRE isolators work as passive components. The VD suspension can adjust its damping in real time while its stiffness is fixed. The current to the MRE isolators is set to be $3 \mathrm{~A}$.

\subsection{Design and testing of the VS isolators and VD dampers}

\subsubsection{Design and testing of the MRE isolators}

MRE is an intelligent material which has been widely used in vibration control [36, 37]. Many scholars have studied the MRE isolator and used it as variable stiffness devices [38, 39]. As a kind of intelligent structure, the stiffness of the MRE device can be controlled by adjusting the current to its electromagnetic coil. What's more, the configuration of the MRE isolator is similar to the air spring of the train, as a result, MRE isolator can be used as smart air spring with variable stiffness characteristics to change the lateral natural frequency of the car body. In other words, it is possible to avoid the lateral resonance of the train body by controlling the stiffness of the MRE isolators.

Figure 2(a) shows the structure and prototype of the proposed MRE isolator developed by our group [40, 41]. This MRE isolator mainly consists of an electromagnetic coil, two permanent magnets, a steel yoke, two steel plate and MRE layers. The two permanent magnets are placed at the ends of the MRE layers which is made of 10 layers of MRE round wafer and 11 layers mild steel bonded together with a strong adhesive. The MRE layers and the permanent magnet are surrounded by an electromagnetic coil, which is placed inside the steel yoke. Two steel plates are mounted to the top and bottom of the permanent magnets, respectively. A gap is left between the upper steel plate and the steel yoke to allow relative movement between top plate and bottom plate.

The working principle of the MRE isolator can be described as follows. Applying currents in different directions to the electromagnetic coil can produce magnetic fields in different directions. This paper defines the direction of the current to be positive when the direction of the magnetic field generated by the current in the electromagnetic coil is the same with the direction of the magnetic field generated by the permanent magnet. Otherwise, the direction of the current in electromagnetic coil is defined as a negative current. When the electromagnetic coil acts as a positive current, the magnetic field in the MRE layers is enhanced. The larger the positive current applied, the stronger the magnetic field in the MRE layers, until the magnetic field saturates. It should be noted that in this study, only positive current was used, however, given the initial isolator stiffness was low. At this time, the horizontal stiffness of the MRE layers gradually increases with the increase of controlling current. The force generated by the MRE isolator can be calculated by [42-44]:

$$
F_{1}=K^{\prime} x+\frac{K^{\prime \prime}}{\Omega} \dot{x}=\frac{G^{\prime} A}{n h} x+\frac{G^{\prime \prime} A}{n h \Omega} \dot{x}
$$

where $K^{\prime}$ is the storage or effective stiffness, $K^{\prime}=G^{\prime} A / h ; K^{\prime \prime}$ is the loss stiffness, $K^{\prime \prime}=$ $G^{\prime \prime} A / h ; K^{\prime \prime} / \Omega$ is the equivalent damping; $x$ and $\dot{x}$ are the displacement and velocity of top steel plate relative to the bottom steel plate, respectively; $\Omega$ is the frequency; $G^{\prime}$ and $G^{\prime \prime}$ are the storage and loss modulus of MRE, respectively, and their relationship to the magnetic field strength are shown in the Appendix (Section A); $A$ and $h$ are the cross sectional areas and thickness of the MRE layers, respectively, $A=\pi(d / 2)^{2}, d$ is the diameter of the MRE layers; $n$ is the number of layers of MRE sheet. 
The dimensions of the MRE isolator are shown in Figure 2(a). The main prototypes parameters of the MRE isolator can be calculated according to the required stiffness of scaled train and are given in Table 2. The wire diameter of electromagnetic coil is $1 \mathrm{~mm}$, and the number of turns of the electromagnetic coils is 1000 .

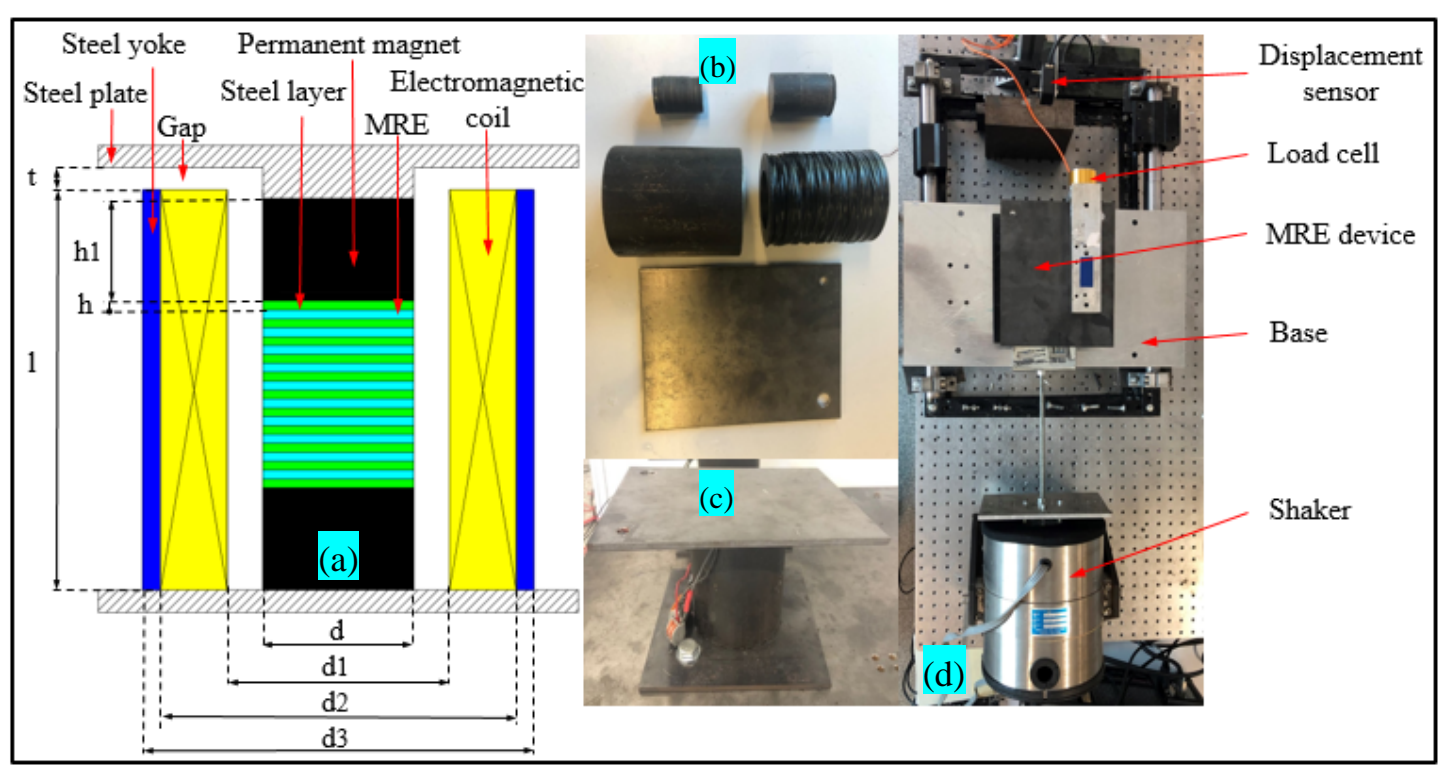

Figure 2. Design, prototype and testing of the MRE isolator: (a) structural schematic, (b) components photograph, (c) assembly photograph, (d) testing system.

Table 2. The main parameters of the MRE isolator.

\begin{tabular}{cccc}
\hline Component & Parameter & Component & Parameter \\
\hline$d(\mathrm{~mm})$ & 35 & $h(\mathrm{~mm})$ & 1.8 \\
$n$ & 10 & $\mathrm{t}(\mathrm{mm})$ & 2 \\
$\mathrm{l}(\mathrm{mm})$ & 90 & $\mathrm{~h}_{1}(\mathrm{~mm})$ & 80 \\
$\mathrm{~d}_{1}(\mathrm{~mm})$ & 50 & $\mathrm{~d}_{2}(\mathrm{~mm})$ & \\
$\mathrm{d}_{3}(\mathrm{~mm})$ & 88 & &
\end{tabular}

In order to analyze the property of the MRE isolator, the magnetic field across the MRE layers are simulated using COMSOL. The simulation results are shown in the Appendix (Section A). Then the force generated by the MRE isolator under external excitation can be calculated according to equation 1. Figure 3 shows the force-displacement relationship of the MRE isolator, with an excitation frequency of $5 \mathrm{~Hz}$ and current varying from $0 \mathrm{~A}$ to $3 \mathrm{~A}$ with a step of $1 \mathrm{~A}$. It can be seen that when a positive current is applied to the MRE isolator, its slope gradually increases with the increase of the current, which means that its stiffness can be controlled by the current.

After the design and analysis, four MRE isolators were manufactured. The physical components and assembly of the MRE isolator are shown in Figure 2(b) and Figure 2(c), respectively. To further explore the dynamic characteristics of the MRE isolator, a series of tests were carried out using the equipment shown in Figure 2(d). The MRE isolator was fixed to the horizontal vibration platform, and the MRE isolator was excited by a shaker that was controlled by a power amplifier and a 
LabVIEW program. The horizontal displacement of the MRE isolator was measured by a laser sensor. The force sensor was connected to the top plate of the MRE isolator for measuring the force in the horizontal direction. During the test, a DC power supply provided current to the electromagnetic coil. The magnitude of the magnetic field crossing MRE layers can be adjusted by the magnitude and direction of the current. The laser sensor and force sensor were connected to a myRIO controller to collect the generated force and excitation displacement. The measured data was recorded to the computer by the LabVIEW program.

Figure 3 also shows testing results of the force-displacement relationship of the MRE isolator, with a test frequency of $5 \mathrm{~Hz}$ and current $I_{S}$ varying from $0 \mathrm{~A}$ to $3 \mathrm{~A}$ with a step of $1 \mathrm{~A}$. It is worth to note that the overall stiffness increases as the current applied to the MRE isolator increases, and the simulation results and experimental results match well with each other. In order to evaluate the influence of the current on the stiffness of the MRE isolator, the effective stiffness is calculated. The calculating formula is as follows [39]:

$=\frac{F_{\max }-F_{\min }}{\Delta_{\max }-\Delta_{\min }}$

where $F_{\max }$ and $F_{\min }$ are the maximum and minimum force values generated by the MRE isolator, respectively. And $\Delta_{\max }$ and $\Delta_{\min }$ represent the maximum and minimum displacements during the test.

The effective stiffness versus current is shown in Table 3, which illustrates that the increase of $I_{S}$ from 0 A to 3 A enhances the stiffness from $4.18 \mathrm{kN} / \mathrm{m}$ to $8.32 \mathrm{kN} / \mathrm{m}$, and the effective stiffness increases by 2 times.

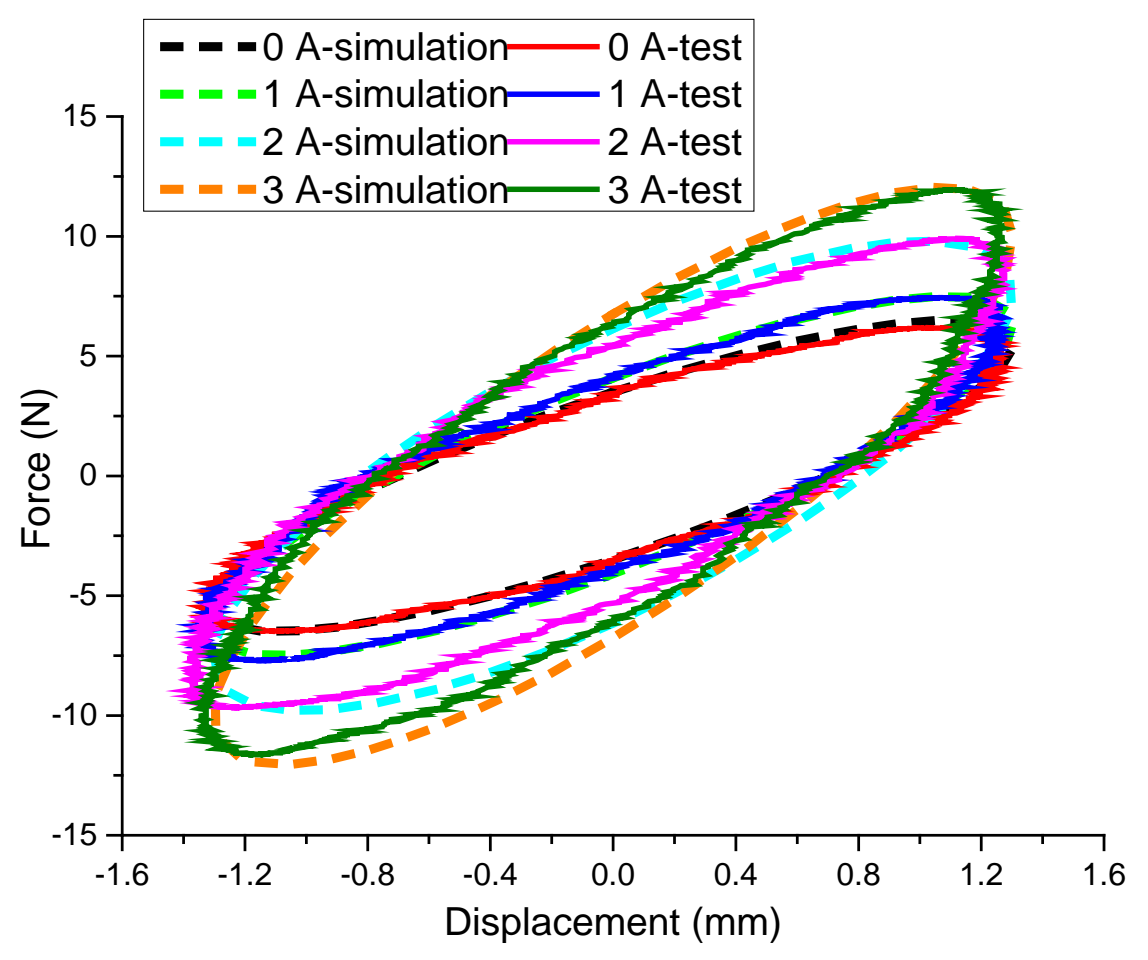

Figure 3. Force-displacement curve of the MRE isolator. 
Table 3. Effective stiffness of the MRE isolator versus $I_{s}$.

\begin{tabular}{ccccc}
\hline$I_{S}(\mathrm{~A})$ & 0 & 1 & 2 & 3 \\
\hline$k_{\text {eff }}(\mathrm{kN} / \mathrm{m})$ & 4.18 & 5.05 & 6.76 & 8.32 \\
\hline
\end{tabular}

\subsubsection{Design and testing of the MR dampers}

Figure 4(a) shows the structure and prototype of the proposed MR damper. This damper mainly consists of piston shaft, piston, electromagnetic coil, hydraulic cylinder, magnetorheological fluid, floating piston and accumulator spring. The electromagnetic coil is wound around the piston. The piston and electromagnetic coil are placed in the hydraulic cylinder, which is filled with MR fluid. An accumulator spring connected to the floating piston is fixed to the bottom cover, and the spring supports the floating piston to provide a preload pressure to the MR fluid. The shaft is connected to the piston and then passes through the top cover which is connected to the cylinder. When the shaft moves in the hydraulic cylinder, the MR fluid flows through the gap between the piston and the cylinder. The larger the current applied to the electromagnetic coil, the larger the magnetic field, and the higher the viscosity of the magnetorheological fluid will be, which enlarge the damping force. The damping force of the MR damper can be calculated as [45-47]:

$$
F_{2}=\frac{12 \eta l A_{p}^{2}}{\pi D h^{3}} v+\frac{3 l \tau_{y} A_{p}}{h} \operatorname{sgnv},
$$

where $\eta$ is the dynamic viscosity of the MR fluid; $l$ is the effective length of the piston, $l=L-$ $L_{1} ; A_{p}$ is the effective area of the piston, $A_{p}=\pi\left(h_{1}+r\right)^{2}-\pi r_{0}{ }^{2} ; h_{1}$ is coil groove depth; $r$ is the core radius; $r_{0}$ is the shaft radius; $D$ is the average diameter of the gap, $D=2\left(h_{1}+r\right)+h$; $h$ is the gap height between the piston and the cylinder; $\tau_{y}$ is the shear yield strength of the MR fluid, and its relationship to the magnetic field strength is shown in Fig. A3 in the Appendix (Section B); $v$ is the speed of movement of the piston relative to the cylinder.

The main parameters of the VD-MR damper can be calculated according to the required damping of scaled train and are given in Table 4. The wire diameter of the electromagnetic coil is $1 \mathrm{~mm}$ and the number of turns of the coil is 90 .

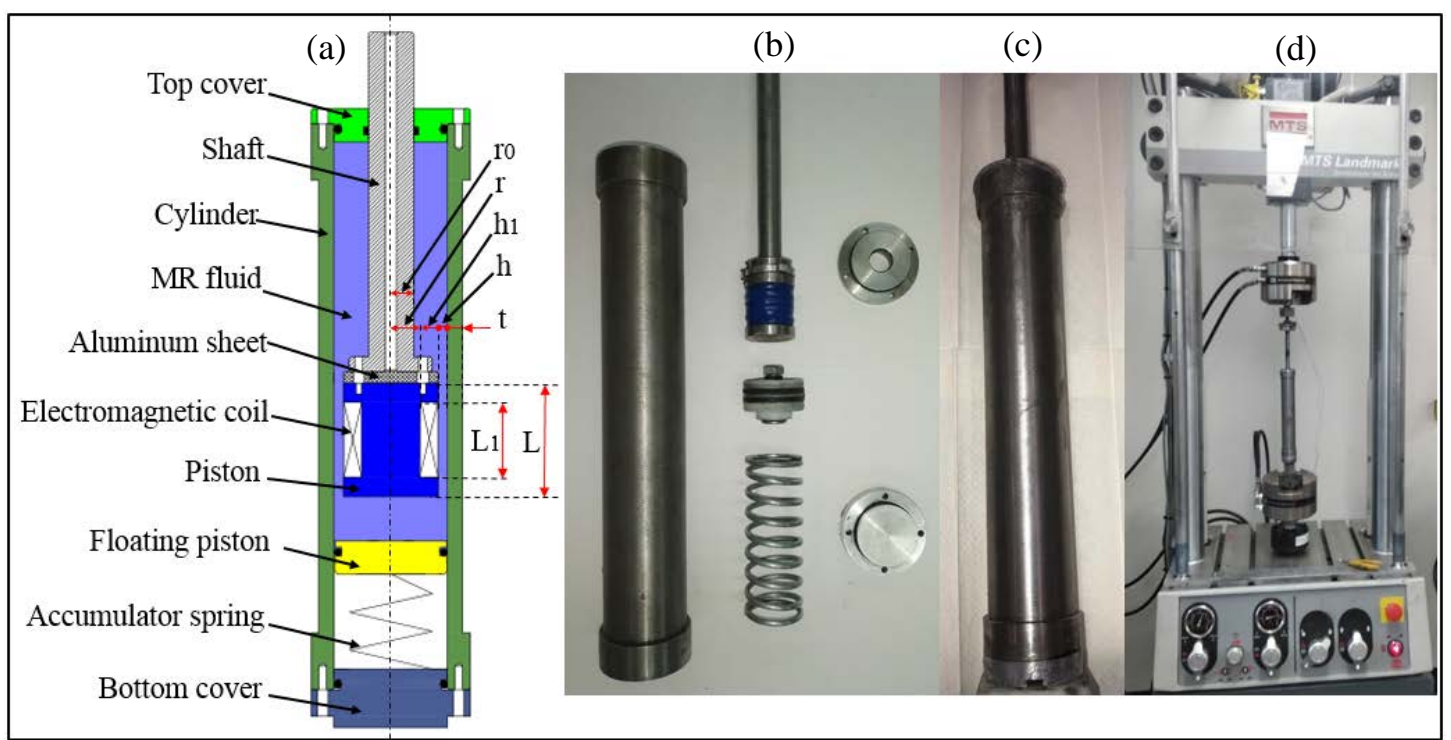


Figure 4. Design, prototype and testing of the MR damper: (a) structural schematic, (b) components photograph, (c) assembly photograph, (d) testing system.

Table 4. The main parameters of the VD-MR damper.

\begin{tabular}{cccc}
\hline Component & Parameter & Component & Parameter \\
\hline$L(\mathrm{~mm})$ & 30 & $r(\mathrm{~mm})$ & 7.5 \\
$h_{1}(\mathrm{~mm})$ & 5 & $h(\mathrm{~mm})$ & 1 \\
$r_{0}(\mathrm{~mm})$ & 6 & $L_{1}(\mathrm{~mm})$ & 20 \\
$t(\mathrm{~mm})$ & 4 & $\eta(\mathrm{Pa} \cdot \mathrm{s})$ & 0.3825 \\
\hline
\end{tabular}

The magnetic field analysis of the MR damper is conducted and is shown in the Appendix (Section B). Then the damping force generated by the MR damper under different currents, excitation frequencies and amplitudes can be calculated using equation 3. The results are shown in Figures 5, 6 and 7 , respectively.

After the analysis, two MR dampers were manufactured. The components and assembly of the MR damper are shown in Figure 4(b) and (c), respectively. The MTS testing was conducted to investigate how the MR damper behaves under a range of conditions. The MTS test system shown in Figure 4(d) consists of a computer, controller, data acquisition board, force sensor, power supply, and hydraulic cylinder. The motion of the hydraulic cylinder can be programmed by computer software and controlled by the controller to move according to a predetermined path, and then transferred the collected data to the computer via a data acquisition board for recording. A harmonic excitation with a single frequency of $3 \mathrm{~Hz}$ and an amplitude of $7 \mathrm{~mm}$ was chosen to excite the system. To obtain the variable damping performance of the damper, the current $I_{d}$ applied to the MR damper was varied from 0 A to $2 \mathrm{~A}$ with a step of $1 \mathrm{~A}$. Then the effect of the excitation frequency and amplitudes on damping coefficient were also tested with different excitation frequencies and amplitudes.

Figure 5 also shows the testing results of the relationship of the damping force and displacement under different currents with the test excitation frequency to be $3 \mathrm{~Hz}$ and the amplitude to be $7 \mathrm{~mm}$. It can be seen that the damping force increases as the current applied and the test results match the simulation results very well. In order to evaluate the magnitude of the damping force under different currents, the effective damping coefficient calculated as follows [39]:

$$
c_{e f f}=E /\left(2 \pi^{2} f X_{0}^{2}\right),
$$

where $X_{0}$ is the excitation amplitude and $f$ is the excitation frequency. The energy dissipated by the MR damper in one cycle, $E$, is represented by the area enclosed within the hysteresis loop, which is given as:

$$
E=\int_{0}^{1 / f} F \dot{z} d t
$$

where $F$ is the force generated by the MR damper and $\dot{z}$ is the piston velocity. 
Table 5 gives the equivalent damping coefficients of the damper under different currents. It can be obtained that the equivalent damping coefficient increase more than 3 times as the increase of the current from 0 A to $2 \mathrm{~A}$.

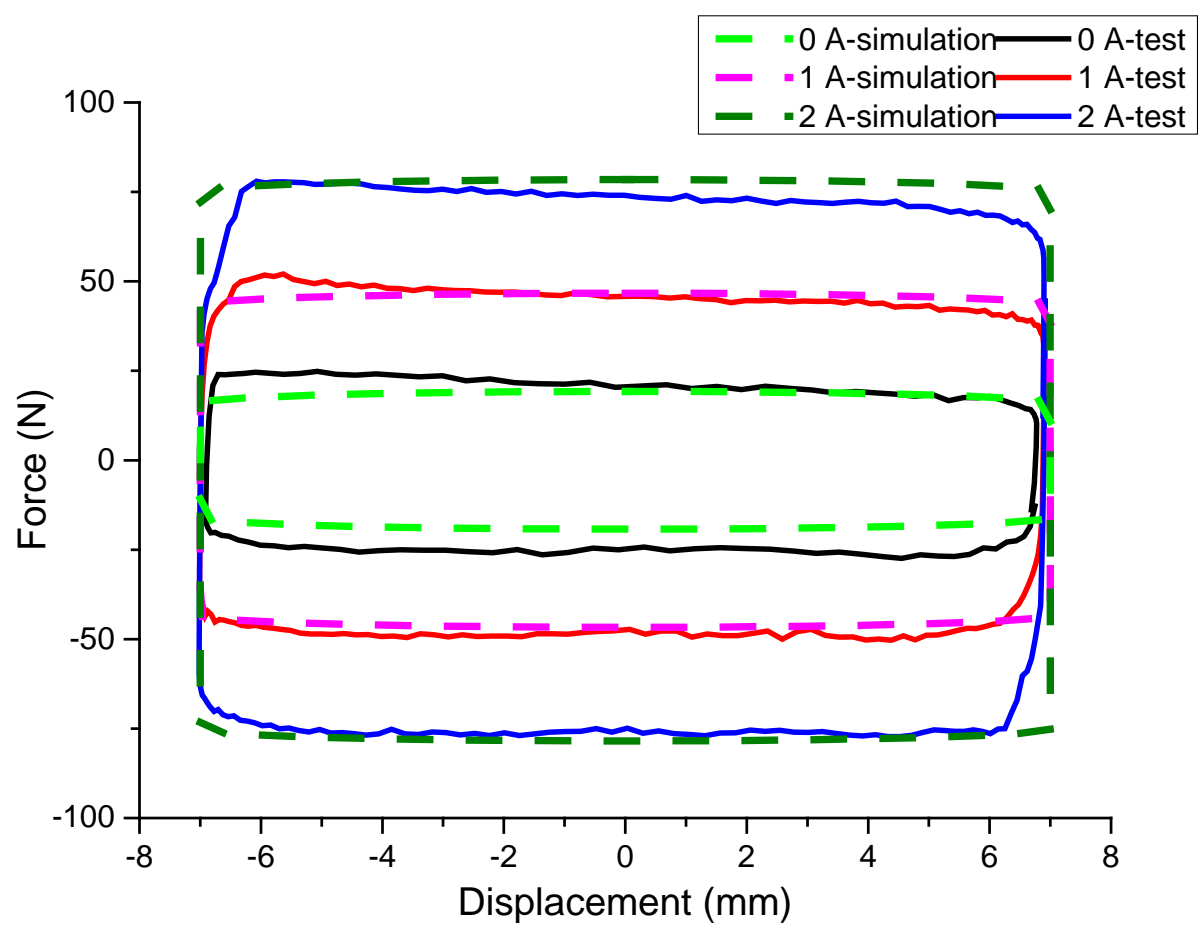

Figure 5. Force-displacement loop of the MR damper under different currents with frequency of 3 $\mathrm{Hz}$ and amplitude of $7 \mathrm{~mm}$.

Table 5. Effective damping coefficient of MR damper.

\begin{tabular}{cccc}
\hline$I_{d}(\mathrm{~A})$ & 0 & 1 & 2 \\
\hline$c_{e f f}(\mathrm{~N} \cdot \mathrm{s} / \mathrm{m})$ & 215.5 & 444.4 & 704.8
\end{tabular}

The influence of the excitation frequency and displacement on damper performance was also conducted and the testing results are given in Figures 6 and 7, respectively. Figure 6 presents the influence of excitation frequency on damper performance with the excitation displacement to be 7 $\mathrm{mm}$ and the current to be $1 \mathrm{~A}$. The excitation frequencies of $1 \mathrm{~Hz}, 3 \mathrm{~Hz}$, and $5 \mathrm{~Hz}$ were used to test the damper as well. It can be seen that the damping force and vibration energy consumption of the damper is not sensitive to the excitation frequency. Figure 7 shows the damping hysteresis loop under different excitation displacements. The excitation frequency is $3 \mathrm{~Hz}$ and the current is $1 \mathrm{~A}$. It can be seen that the maximum damping force does not change when the same frequency and the same current act. As a result, the excitation amplitude barely affects the damping force of the MR damper either. According to the above analysis, the frequency and displacement of the MR damper barely affect the damper performance. It can also be seen from the figures that the simulation results fit the testing results well. 


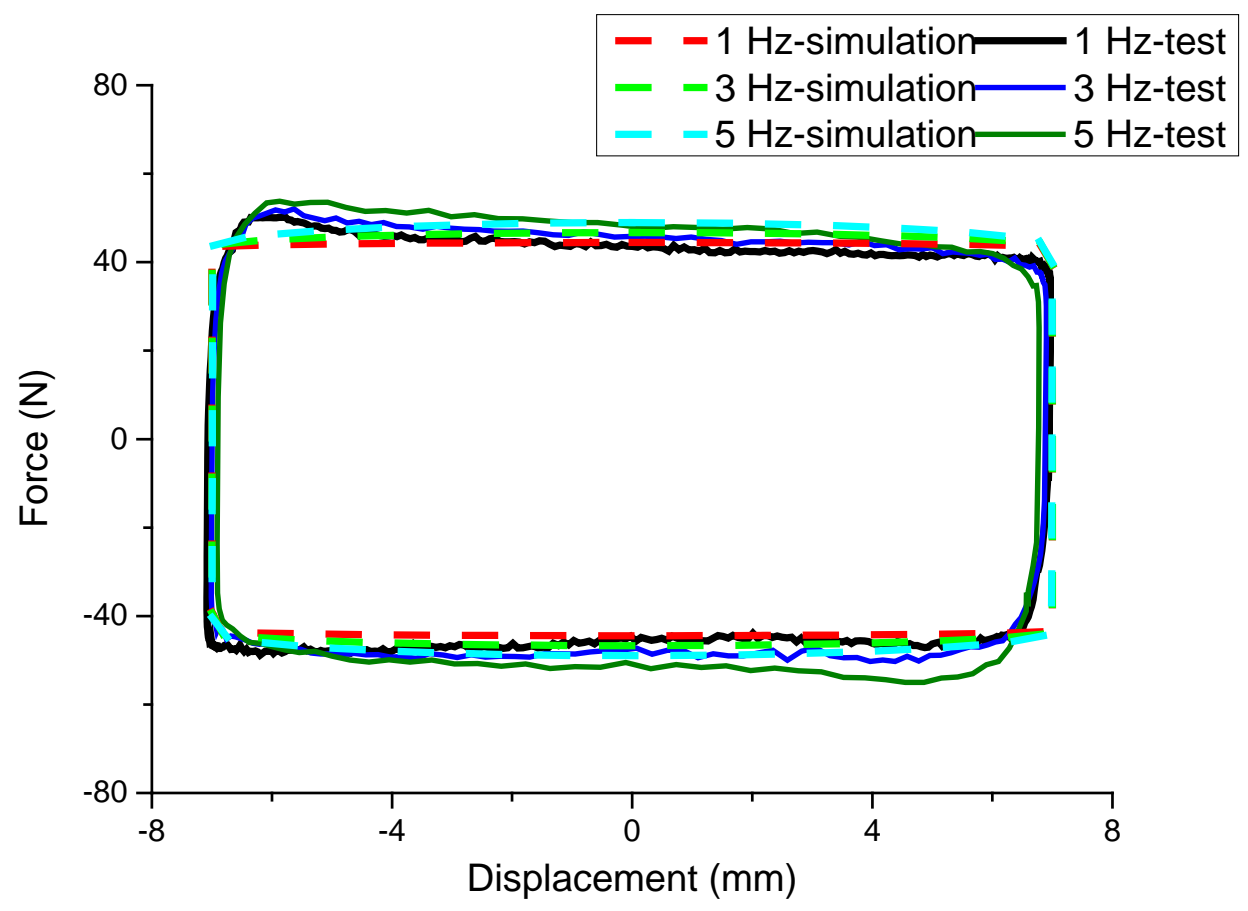

Figure 6. Force-displacement curve of MR damper under different frequency with current of $1 \mathrm{~A}$ and amplitude of $7 \mathrm{~mm}$.

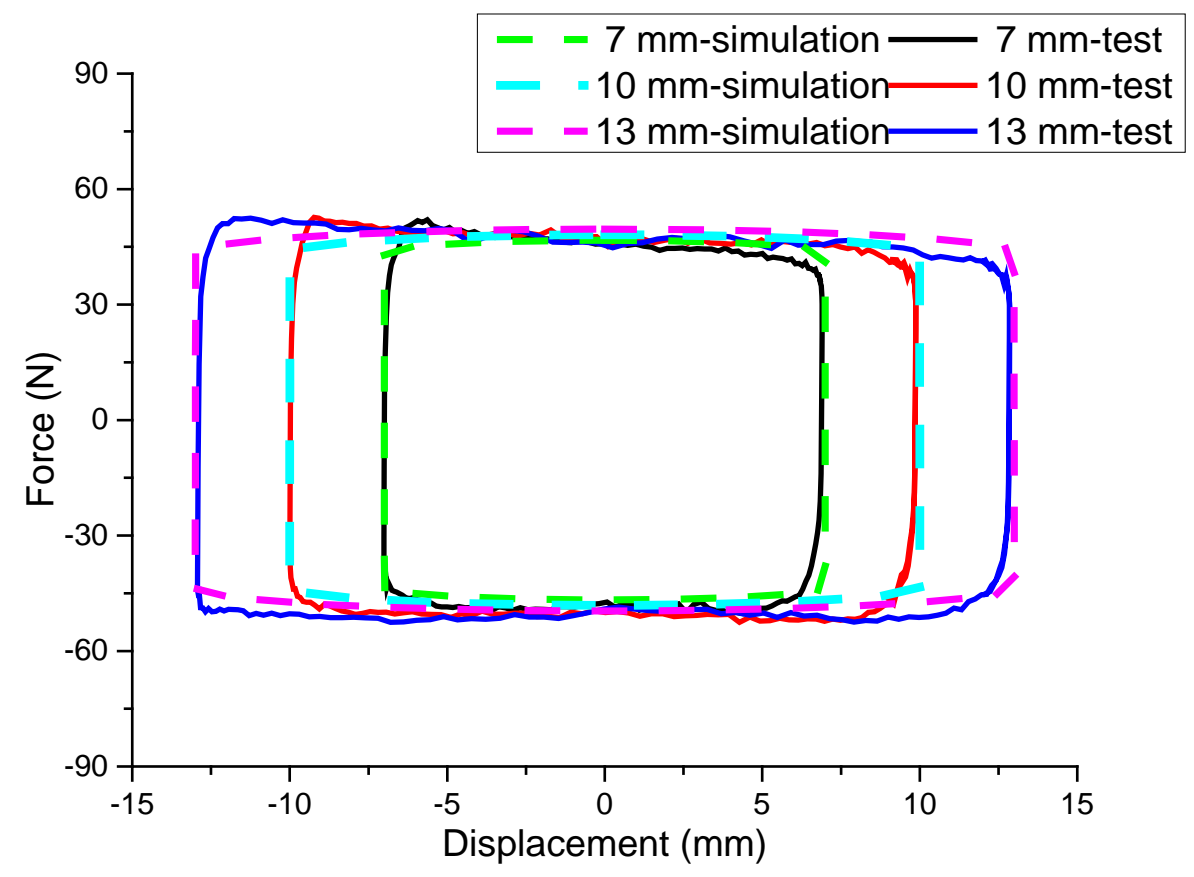

Figure 7. Force-displacement curve of MR damper under different amplitude with current of $1 \mathrm{~A}$ and frequency of $3 \mathrm{~Hz}$.

3. Experiment testing and analysis of the versatile VSVD semi-active suspension for railway vehicle 


\subsection{A scaled train testing system}

Figure 8 shows the prototype and experiment setup of the small-scale railway vehicle testing system. This system mainly includes two laser displacement sensors, two acceleration sensors, a support plate, a 6-degrees-of-freedom (6-DOF) vibration platform, a railway vehicle car body model and the suspension system. The displacements and accelerations of the vehicle car body and the support plate are tested by two displacement sensors and the two accelerometers, respectively. The support plate is fixed on the 6-DOF vibration platform. The 6-DOF vibration platform can provide lateral vibration excitation to the vehicle to simulate the real excitation from bogie to car body. The suspension system consists of four MRE isolators and two MR dampers that are mounted between the car body and the support plate to provide lateral stiffness and damping force, respectively.

The details of the testing system are also shown in Figure 8. The set excitation displacement signal is read by the LabVIEW software in PC 1 . Then six hydraulic cylinders are controlled by NI CompactRio controller to trace the set excitation displacement, and drive the 6-DOF vibration platform to move. The support plate moves along with the 6-DOF vibration platform and transmits the vibration excitation through the suspension system to the car body. The lateral displacements are measured by laser displacement sensors, and the lateral accelerations are measured by accelerometers. The displacement and acceleration signals are recorded and stored in the PC 2 via the NI myRIO controller. After the data is analyzed by the computer software LabVIEW using the control algorithm, the voltage control signal is sent to the NI myRIO controller. Then the NI myRIO controller controls the power amplifiers to generate control current $I_{S}$ to the MRE isolators and control current $I_{d}$ to the MR dampers to change the stiffness and damping of the suspension system. Thereby realizing real-time control of the VSVD semi-active suspension system of the railway vehicle.

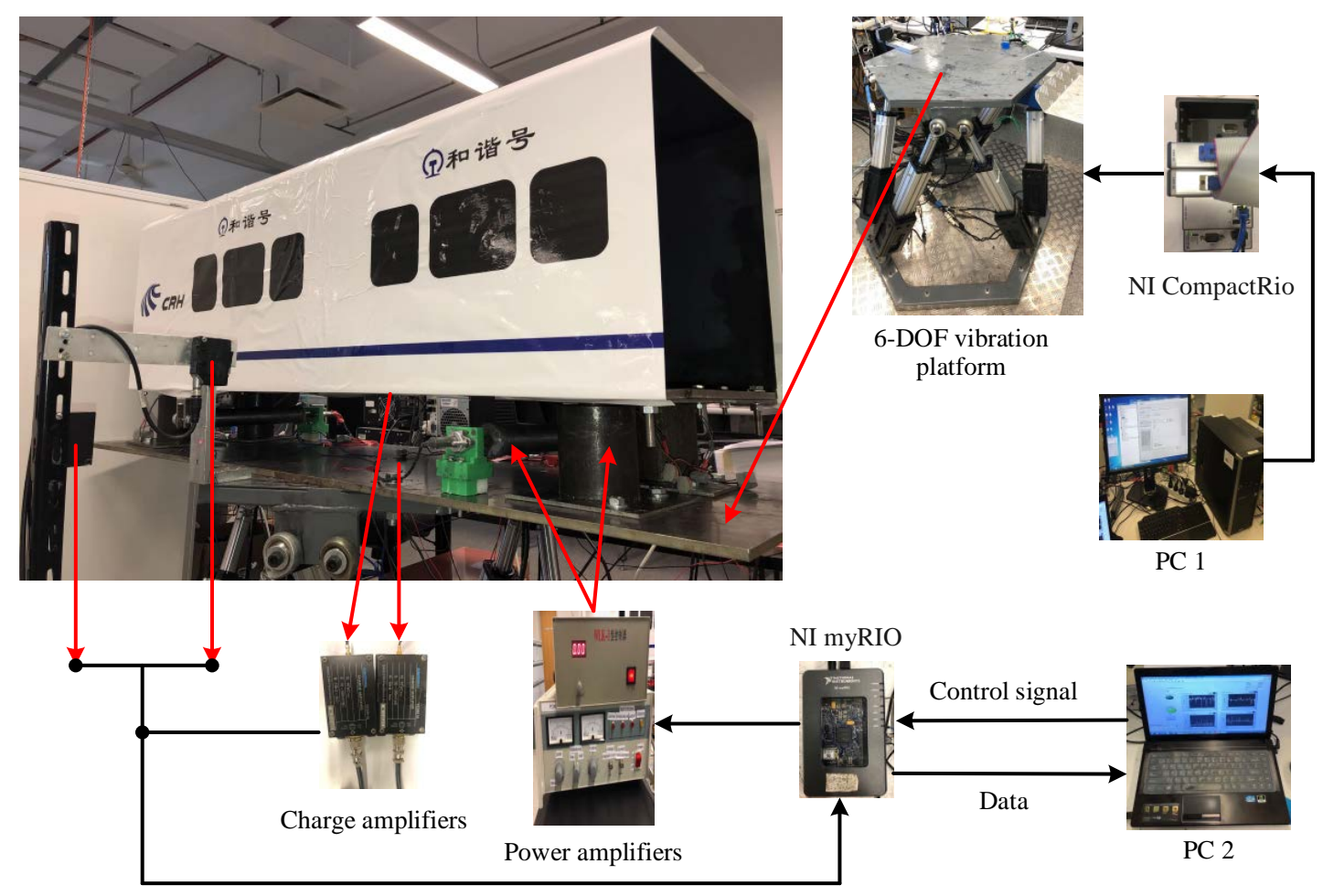

Figure 8. Test system of the railway vehicle with VSVD semi-active suspension. 


\subsection{Controller design for the versatile semi-active suspension}

In this section, a VS controller based on STFT to avoid the lateral resonance of the car body and a VD controller based on sky-hook for better improving the ride comfort of the high-speed railway vehicle were designed. The dynamic performance of the vehicle installed with the controlled suspension system under harmonic excitation and random excitation is evaluated and analyzed. As a comparison, the experiments of the high-speed railway vehicle installed with passive suspension, VS suspension, and VD suspension were also conducted.

Since the stiffness and damping of the semi-active suspension system for the railway vehicle are separately controlled in real time, two different control strategies have been designed for the MRE isolators and the MR dampers respectively. For the VS controller, the track excitation frequency increases with the increase of the running speed; the lateral resonance frequency of the railway vehicle car body with passive suspension is fixed; thus, lateral resonance of the car body at a certain running speed [37] will occur during train's accelerating. In order to avoid the lateral resonance of the car body and pick the stiffness changing frequency, the vehicle lateral vibration transmission rate of large stiffness $\left(I_{s}=3 \mathrm{~A}\right)$ and small stiffness $\left(I_{s}=0 \mathrm{~A}\right)$ of the MRE isolators was tested firstly. Figure 9 is a plot of lateral vibration transmissibility as a function of harmonic excitation frequency with a lateral excitation amplitude of $1 \mathrm{~mm}$ and the excitation frequency varying from 1 $\mathrm{Hz}$ to $5.5 \mathrm{~Hz}$. The calculation formula of the vibration transmission rate is as follows:

$=\frac{R M S\left(y_{c}\right)}{R M S\left(y_{b}\right)}$.

Where $\eta$ is the lateral vibration transmissibility from the bogie to the car body of the railway vehicle, and $\operatorname{RMS}\left(y_{c}\right)$ and $\operatorname{RMS}\left(y_{b}\right)$ are the Root-Mean-Square (RMS) values of the car body displacement and the bogie displacement, respectively.

It can be seen that if the large stiffness is taken as the stiffness of the passive suspension system, the vehicle car body will experience lateral resonance near the excitation frequency of 3.5 Hz. When the small stiffness is chosen for the suspension system, the lateral vibration transmission at the frequency of $3.5 \mathrm{~Hz}$ is greatly reduced. The vibration transmission of the large stiffness and the small stiffness cross at the excitation frequency of $3.1 \mathrm{~Hz}$, which is defined as switching frequency $f_{0}$. The ideal scenario is to control the stiffness of the suspension to be soft when the excitation frequency is higher than $3.1 \mathrm{~Hz}$ and to be hard when the excitation frequency is lower than $3.1 \mathrm{~Hz}$. Then the minimum transmissibility can be achieved. The detailed control strategy is expressed as:

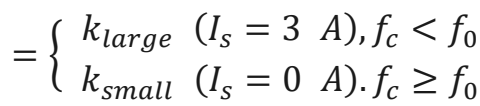

$k_{y}$

Where $k_{\text {large }}$ and $k_{\text {small }}$ are the maximum and minimum stiffness of the MRE isolator, respectively; $f_{c}$ is the dominant frequency of the vibration, which is obtained by STFT of the lateral displacement of the bogie. The calculation formula of $f_{c}$ using STFT is as follows:

$=y(t) \varphi(t$

$-\tau)$ 
where $\tau$ is the fixed time, and $t$ is the running time. $y_{\tau}(t)$ is a conversion function, and $\varphi(t)$ is a window function. $y(t)$ is the lateral displacement signal from bogie of the train.

Then the Fourier transform for the modified signal is calculated as (9).

$$
Y_{\tau}(\omega)=\frac{1}{\sqrt{2 \pi}} \int y(t) \varphi(t-\tau) e^{-j \omega t} d t .
$$

The energy density of the windowed signal at the fixed time $\tau$ can be calculated, which can provide the time-frequency distribution.

$$
\mathrm{P}(\tau, \omega)=\left|Y_{\tau}(\omega)\right|^{2}=\left|\frac{1}{\sqrt{2 \pi}} \int y(t) \varphi(t-\tau) e^{-j \omega t} d t\right|^{2} .
$$

The instantaneous frequency at time $\tau$ is given by

$$
f_{c}(\tau)=\omega_{\tau}=\frac{1}{|y(\tau)|^{2}} \int \omega\left|Y_{\tau}(\omega)\right|^{2} d \omega .
$$

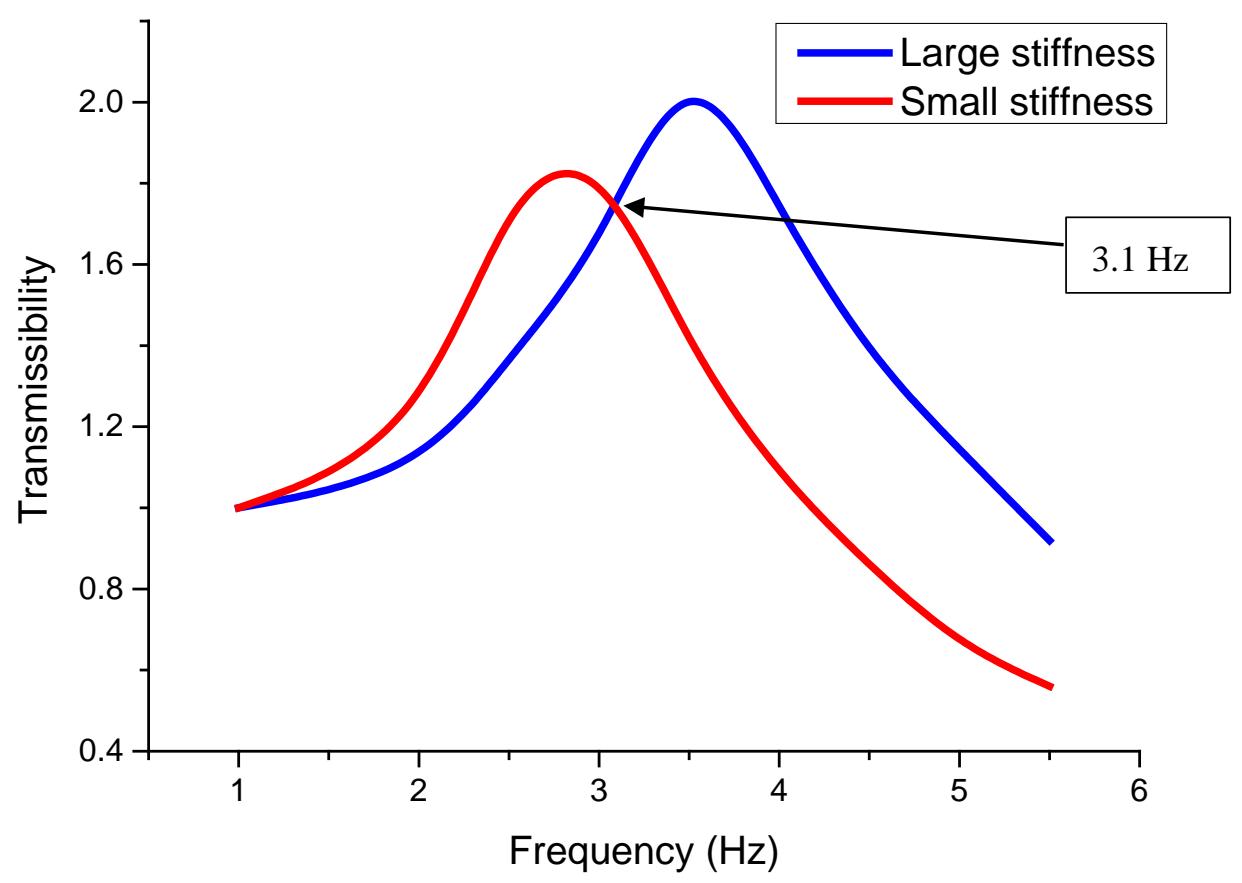

Figure 9. Transmissibility of the suspension system with large and small lateral stiffness.

As for the VD controller, the classic sky-hook controller was chosen, which is reliable and practical. The sky-hook controller can be described as:

$$
c_{y}= \begin{cases}c_{\text {large }}\left(I_{d}=1 A\right), \dot{y}_{c} \cdot\left(\dot{y}_{c}-\dot{y}_{b}\right) \geq 0 \\ c_{\text {small }}\left(I_{d}=0 A\right) \cdot \dot{y}_{c} \cdot\left(\dot{y}_{c}-\dot{y}_{b}\right)<0\end{cases}
$$

Where $c_{\text {large }}$ and $c_{\text {small }}$ are the large damping under $1 \mathrm{~A}$ current energizing and small damping under 0 A current, respectively; $\dot{y}_{b}$ and $\dot{y}_{c}$ are the lateral velocity of the car body and the support plate, respectively.

\subsection{Evaluation and analysis of different suspension systems}


Case 1: evaluation under harmonic excitation.

Figure 10 presents the acceleration of the car body controlled by VSVD suspension system, as well as the acceleration of car body controlled by pure VS, pure VD, passive-off, and passive-on suspension systems, as comparison. The five different suspensions were under harmonic excitation with amplitude of $1 \mathrm{~mm}$ and frequency of $3.5 \mathrm{~Hz}$. It can be seen that the passive-off suspension system performs the worst, followed by the VS suspension system. The performance of the VD and passive-on suspension system is better than that of the VS suspension system. Obviously, the VSVD suspension system outperforms the other four suspension systems in reducing the acceleration of the car body. In order to quantify the vibration reduction performance of these five suspension systems, Table 6 gives the RMS values of the car body vibrations. It can be seen that the RMS values of the passive-on suspension, VS suspension, VD suspension and VSVD suspension are reduced by $54.7 \%, 41.6 \%, 56.7 \%$ and $68.8 \%$ compared with the passive suspension, respectively.

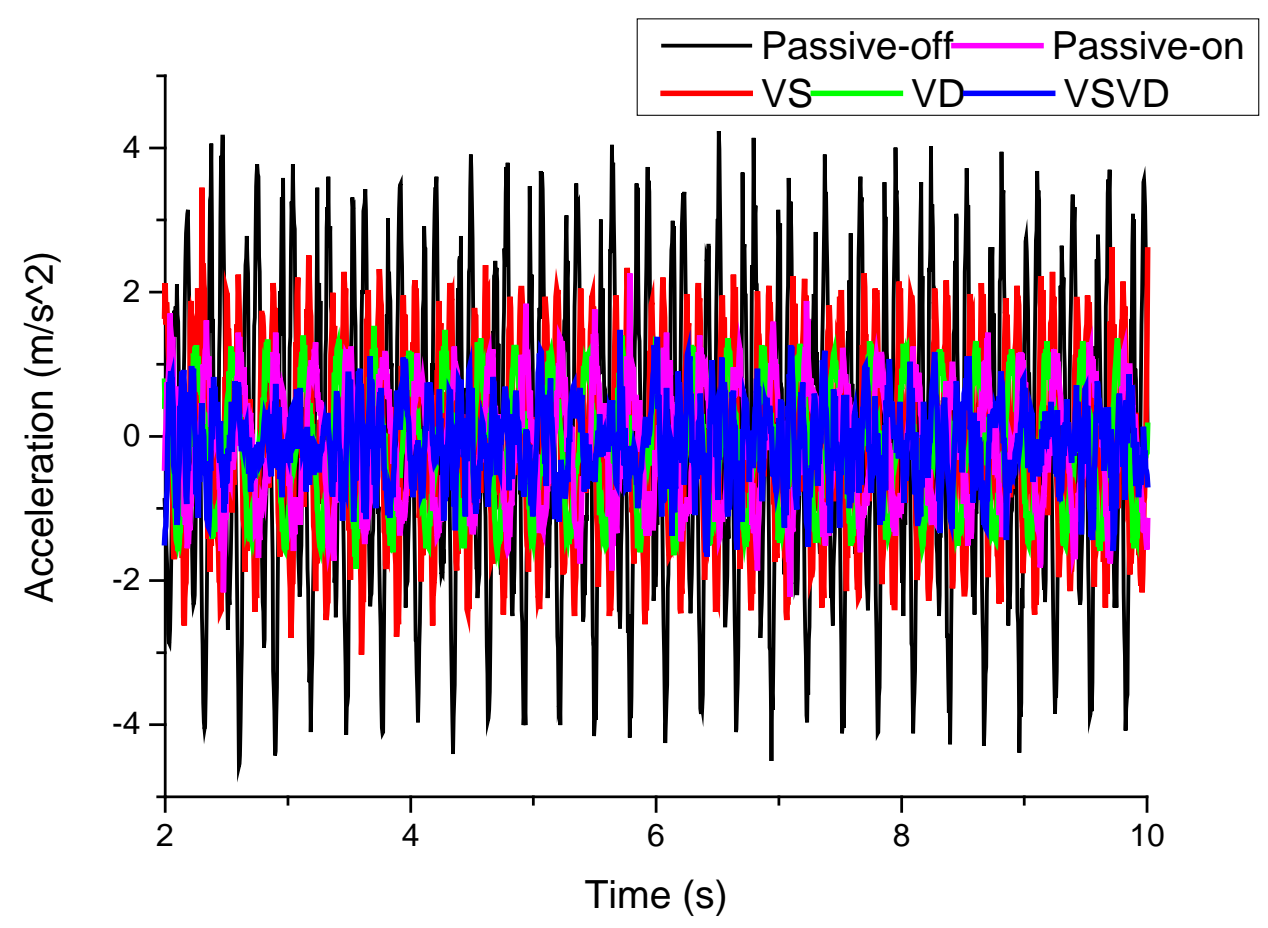

Figure 10. Car body acceleration under sinusoidal excitation in time domain.

Table 6. RMS values of the car body under sinusoidal excitation.

\begin{tabular}{cccccc}
\hline Body & Passive-off & Passive-on & VS & VD & VSVD \\
\hline RMS-acceleration $\left(\mathrm{m} / \mathrm{s}^{2}\right)$ & 1.7703 & 0.8017 & 1.0338 & 0.7663 & 0.5526 \\
Reduce proportion & NA & $54.7 \%$ & $41.6 \%$ & $56.7 \%$ & $68.8 \%$ \\
\hline
\end{tabular}

To further compare the vibration attenuation ability of the four suspension systems at different excitation frequencies, the vibration transmissibility of the railway vehicle under different excitation frequencies was tested experimentally, as shown in Figure 11. It can be seen that when the excitation frequency is lower than the switching frequency $\left(f_{0}\right)$, the transmissibility of the pure VS suspension is identical to the passive-off suspension and the transmissibility of the VD suspension is the 
smallest. The transmissibility of the VSVD suspension is slightly higher than that of the VD suspension, but lower than the passive-on suspension, VS suspension and the passive-off suspension. At the switching frequency, the transmissibility of the VSVD suspension and pure VS suspension reach the maximum. When the excitation frequency is higher than $f_{0}$, the transmissibility of the passive-on suspension, VS suspension and the VD suspension is lower than that of the passive-off suspension, and the transmissibility of the VSVD suspension is much lower than that of the other four suspension. As the excitation frequency continues to increase, the transmissibility of the pure VD suspension and passive-on suspension will be higher than the passive suspension. At the same time, the transmissibility rate of the VSVD suspension will be slightly higher than the pure VS suspension but will still be lower than the passive-off suspension, passive-on suspension and pure VD suspension. It is worth noting that the passive-on suspension is always higher than the VD suspension, which may be due to the excessive damping generated by the passive-on MR damper. Based on the above analysis, it can be concluded that the VSVD suspension possesses the best vibration reduction capacity, compared with passive-off suspension, passive-on suspension, pure VS suspension and pure VD suspension considering wide frequency range.

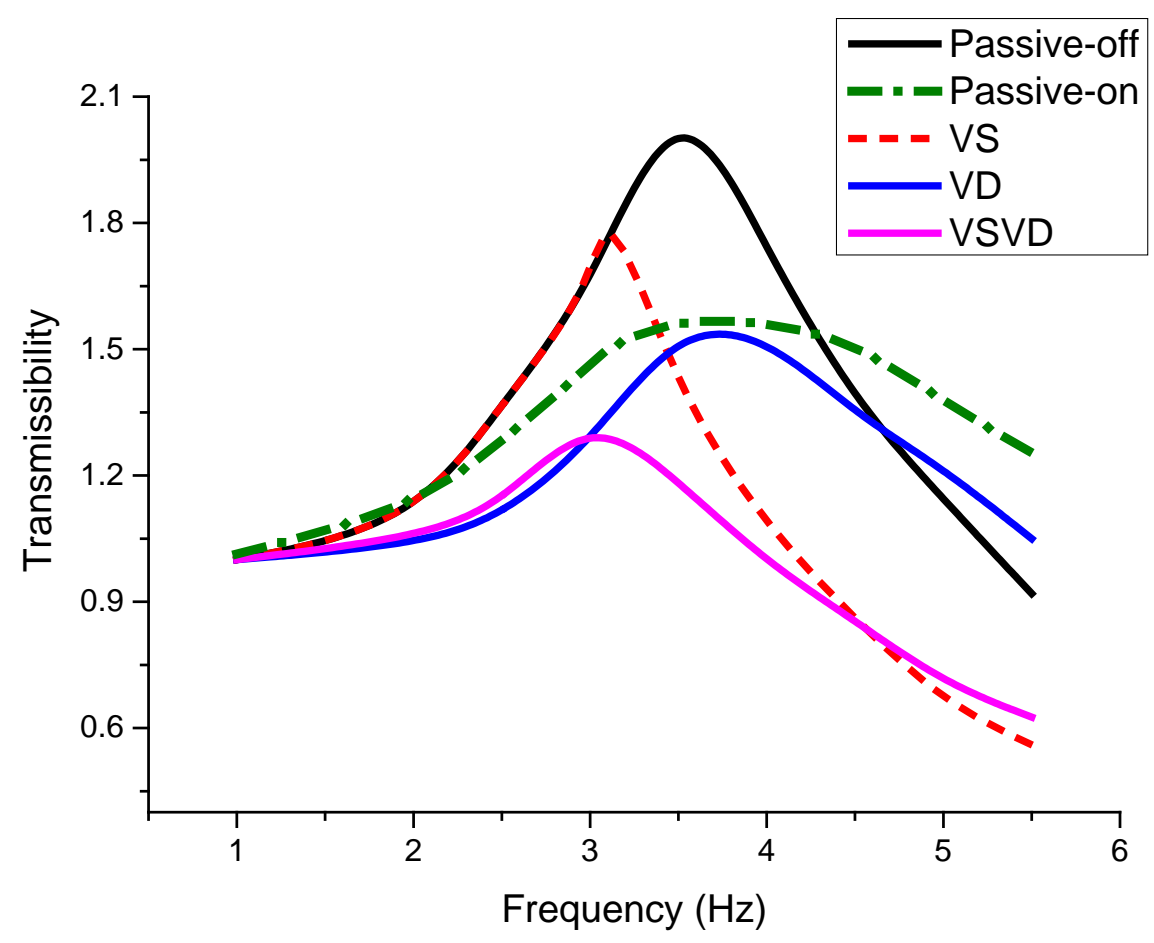

Figure 11. Transmissibility of different suspension systems.

Case 2: evaluation under random excitation.

After the evaluation under harmonic excitation, the performance of different suspension systems under random excitation was also conducted to understand the performance of the suspensions under real excitation. In this test, the random excitation was generated from a high-speed train model running on a track irregularity generated by German power spectral density functions [24-26, 33]. Figures 12 and 13 present the testing results, the acceleration of car body, in time domain and frequency domain, respectively. It can be seen that the vibration reduction ability of the five suspension systems under random excitation is consistent with the vibration reduction ability under 
harmonic excitation. In particular, the VSVD suspension system performs the best on vibration reduction, followed by pure VD suspension, pure VS suspension and passive-on suspension. The passive-off suspension shows the worst performance. Table 7 shows the RMS values of the five different suspension systems under random excitation. The RMS values of the passive-on suspension, VS suspension, VD suspension and VSVD suspension reduce by 4.0\%, 31.3\%, 44.2\% and $55.7 \%$ compared with passive-off suspension, respectively. It can be seen that the VSVD suspension system performs the best compared with passive-off suspension, passive-on suspension, pure VS suspension and pure VD suspension systems.

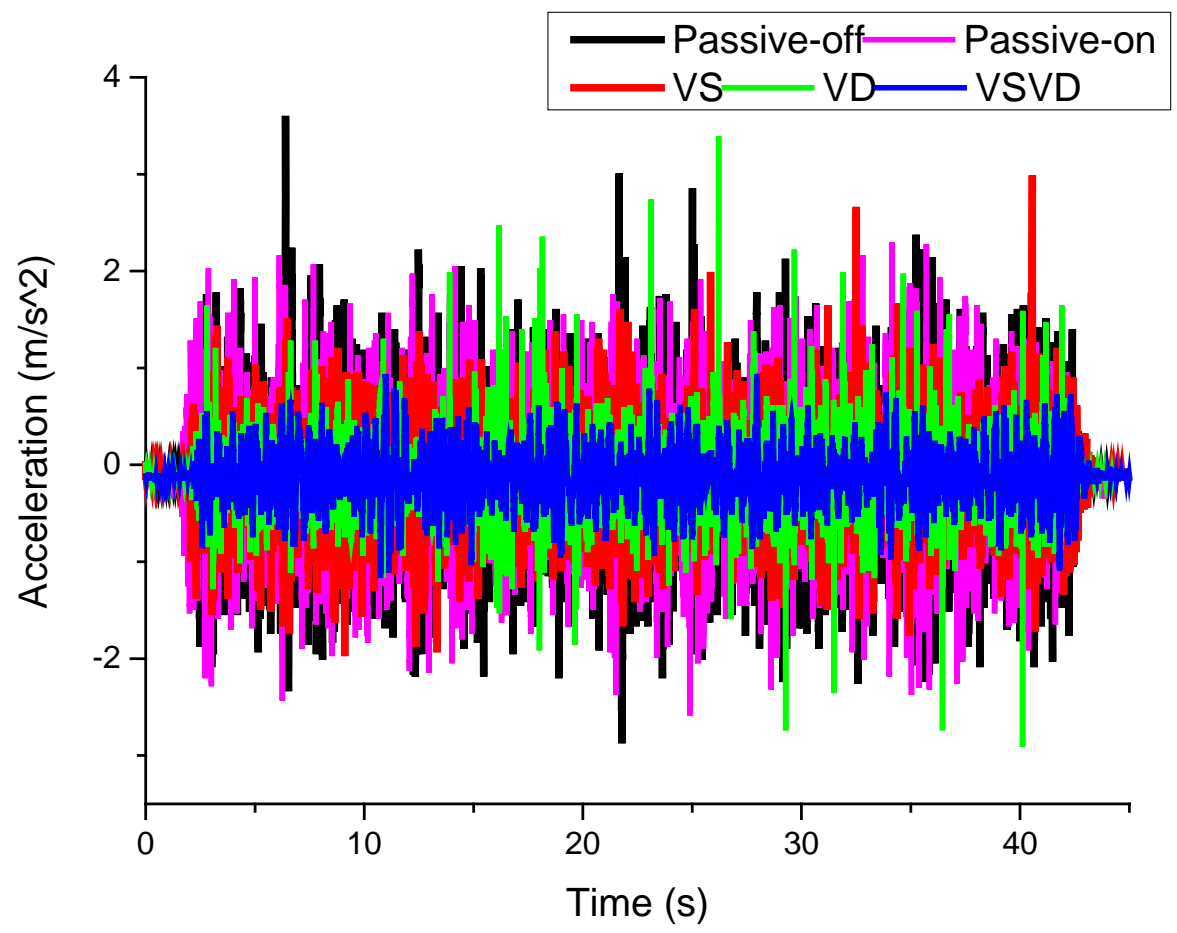

Figure 12. Car body acceleration under random excitation in time domain. 


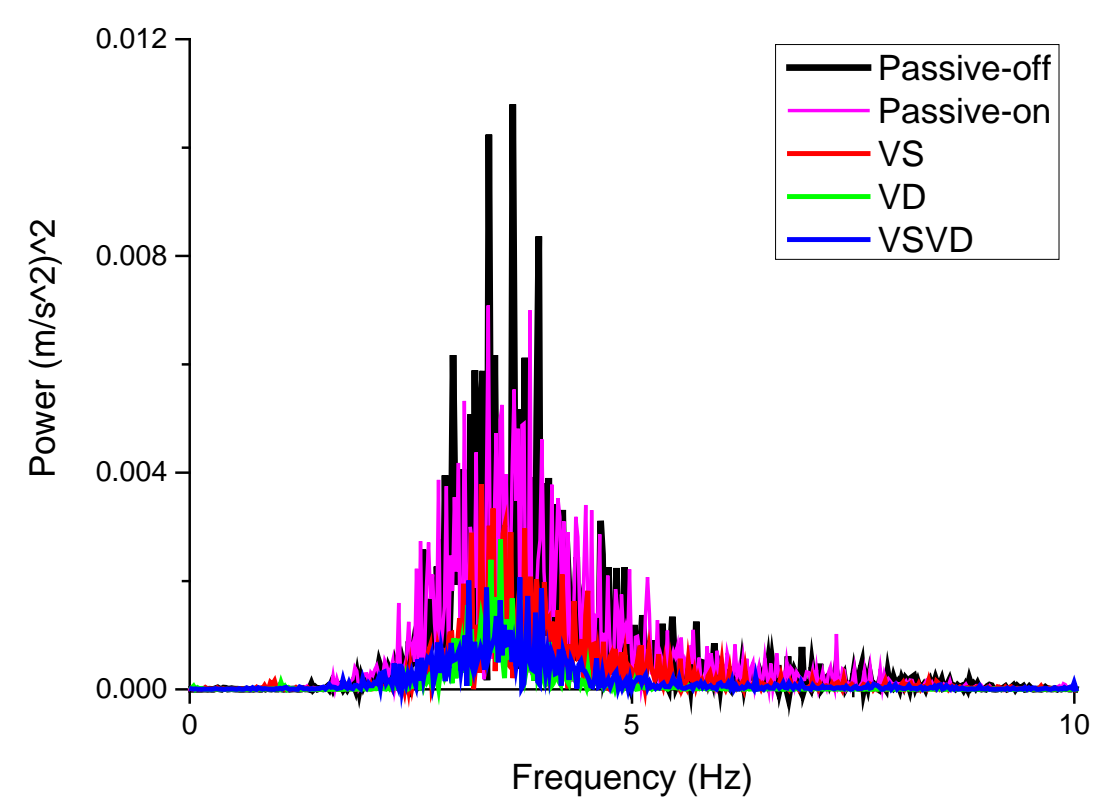

Figure 13. Car body acceleration under random excitation in frequency domain.

Table 7. RMS values of the car body under random excitation.

\begin{tabular}{cccccc}
\hline Body & Passive-off & Passive-on & VS & VD & VSVD \\
\hline $\begin{array}{c}\text { RMS-acceleration (m/ } \\
\left.s^{2}\right)\end{array}$ & 0.7208 & 0.6917 & 0.4950 & 0.4024 & 0.3196 \\
Reduce proportion & NA & $4.0 \%$ & $31.3 \%$ & $44.2 \%$ & $55.7 \%$ \\
\hline
\end{tabular}

3.4 Discussion of the scalability and fail-safe property of the VSVD suspension system

The lateral stiffness and damping of the actual secondary suspension system of high-speed train are approximately $170000 \mathrm{~N} / \mathrm{m}$ and $28000 \mathrm{~N} \cdot \mathrm{s} / \mathrm{m}$, respectively. If the dimensions of the MRE isolator and MR damper in this paper are increased to a certain extent, their stiffness and damping can meet the actual needs of a full-scale train suspension system. Actually, some scholars [26, 48] have designed large scaled MRE isolators and MR dampers. For instance, Zong et al. [26] designed and machined a full-size MR damper for a full-scale high-speed railway vehicle; Yarra et al. [48] designed and fabricated a large-scale MRE isolator for highway bridges. Therefore, it is fully achievable to design a full-scale MRE isolator and MR damper for an actual high-speed railway vehicle.

In fact, the VSVD semi-active suspension system is also facing the possibility of failure. If the MRE isolators fail, the VSVD suspension system will degenerate into a VD suspension system, and its vibration attenuating capability will be weakened; if the MR dampers fails, the VSVD suspension will operate as a VS suspension, and its capability to attenuate vibration will also decrease; if the MRE isolators and the MR dampers fail simultaneously, then the VSVD suspension system becomes a passive suspension system, the ride comfortable will be further reduced; however, when any of these failure conditions occur, the suspension system can still work passively without causing stability issue of high-speed train because there is no external power being added to the suspension system. Therefore, the versatile semi-active suspension system designed and developed in this research has fail-safe characteristics as well. 


\section{Conclusion}

In this paper, an innovative VSVD semi-active suspension system has been successfully designed, prototyped, and evaluated for high-speed railway vehicles. The VSVD suspension system consists of four MRE isolators and two MR dampers. The performance of the MRE isolator and the MR damper were simulated and tested separately, with their capabilities of stiffness and damping controllability having been successfully verified. In order to evaluate the effect of the VSVD semiactive suspension system on the vibration of the railway vehicle, a small-scale train was designed and manufactured as well as a vibration test system. A controller based on STFT and sky-hook was designed and implemented to facilitate the semi-active control of the system. The experimental evaluation for the new VSVD train suspension system was successfully carried out under harmonic and random excitations. The testing results show that the systemcan avoid lateral resonance of the car body and dissipate the vibration energy efficiently. This system performs better in improving ride comfort of the high-speed train compared with the pure VS suspension, pure VD suspension, passive-off, and passive-on suspension systems.

Supplementary Material: a video comparing the performance of the VSVD suspension system and the passive suspension system on vibration control has been uploaded.

\section{Acknowledgements}

Financial supports from the Major Research Plan of the National Natural Science Foundation of China (11790281), the National Key Research and Development Program of China (2016YFB1200501), the National Natural Science Foundation of China (51575036) and Australian Research Council's Linkage Projects (project number LP150100040, LP160100132).

\section{References}

[1] J. Han, Y. Hayashi, P. Jia, et al. Economic effect of high-speed rail: empirical analysis of Shinkansen's impact on industrial location. Journal of Transportation Engineering, 2012, 138(12), pp. 1551-1557. DOI: 10.1061/ (ASCE) TE. 1943-5436.0000467.

[2] G.W. Yang, Y.J. Wei, G.L. Zhao, et al. Research progress on the mechanics of high speed rails (in Chinese). Advances in mechanics, 2015, 45(00), pp. 217-460. DOI: 10.6052/ 1000- 0992- $14-$ 002.

[3] M.R. Chi, W.H. Zhang, J. Zeng, et al. Study of suspension parameter of high speed passenger car bogies (in Chinese). Journal of Dalian Jiaotong University, 2007, 28(3), pp. 13-19. DOI:10.13291/j.cnki.djdxac.2007.03.004.

[4] D. Younesian, A. Nankali. Spectral Optimization of the Suspension System of High-speed Trains. International Journal Vehicle Structures \& Systems, 2009, 1(4), pp. 98-103. DOI: $\underline{10.4273 / \text { ijvss.1.4.07. }}$

[5] Z. Qin, S.X. Zhou, C.L. Sun, et al. Influence of hydraulic shock absorber characteristic parameters on the critical speed of high-speed trains (in Chinese). Journal of Mechanical Engineering, 2017, 53(6), pp. 138-144. DOI: 10.3901/JME.2017.06.138.

[6] T.H. JIN, Z.M. LIU, Z.S. Ren, et al. Study of Combination Damping Characteristics Effect of High- Speed Train Damper(in Chinese). Journal of South China University of Technology (Natural 
Science Edition), 2018, 46(09), pp. 116-124. DOI: 10. 3969/j.issn.1000- 565X. 2018. 09. 016.

[7] Y. Maruyama, K. Ishihara, T. Matsui, et al. Development of an active suspension system for railway vehicles. The Sumltomo Search, 1997, (59), pp. 108-112.

[8] A. Orvnäs, S. Stichel, and R. Persson. Active lateral secondary suspension with Ho control to improve ride comfort: simulations on a full-scale model. Vehicle System Dynamics, 2011, 49(9), pp. 1409- 1422. DOI: 10.1080/00423114.2010.527011.

[9] A. Qazizadeh. On Active Suspension in Rail Vehicles. Doctoral Thesis, 2017, KTH Royal Institute of Technology.

[10] D. Karnopp. Design principles for vibration control systems using semi-active dampers. Journal of Dynamic Systems, Measurement, and Control, 1990, 112(3), pp. 448-455. DOI: $\underline{10.1115 / 1.2896163 .}$

[11] M. Yu, C.R. Liao, W.M. Chen, et al. Study on MR semi-active suspension system and its road testing. Journal of Intelligent Material Systems and Structures, 2006, 17(8-9), pp. 801-806. DOI: $10.1177 / 1045389 X 06057534$.

[12] J.Q. Yu, X.M. Dong and W. Wang. Prototype and test of a novel rotary magnetorheological damper based on helical flow. Smart Materials and Structures, 2016, 25(2), pp. 1-15. DOI:10.1088/0964-1726/25/2/025006.

[13] X.X. Bai, S. Shen, N.M. Wereley, et al. Controllability of magnetorheological shock absorber: I. Insights, modeling and simulation. Smart Materials and Structures, 2019, 28(1), pp. 1-18. DOI: $\underline{10.1088 / 1361-665 X / a a f 072 . ~}$

[14] L.A.A. Powell, Y.T. Choi, W. Hu, et al. Nonlinear modeling of adaptive magnetorheological landing gear dampers under impact conditions. Smart Materials and Structures, 2016, 25(11), pp. 1-11. DOI: 10.1088/0964-1726/25/11/115011.

[15] D. Guan, X.J. Jing, H. Shen, et al. Test and simulation the failure characteristics of twin tube shock absorber. Mechanical Systems and Signal Processing, 2019, 122, pp. 707-719. DOI: 10.1016/j.ymssp.2018.12.052.

[16] Y.Q. Guo, W.H. Xie and X.J. Jing. Study on Structures Incorporated with MR Damping Material Based on PSO Algorithm. Frontiers in Materials, 2019. DOI: 10.3389/fmats.2019.00037.

[17] A. Stribersky, A. Kienberger, G. Wagner, et al. Design and evaluation of a semi-active damping system for rail vehicles. Vehicle System Dynamic, 1998, 29(S1), pp. 669-681. DOI: $10.1080 / 00423119808969594$.

[18] S.S. Sun, H.X. Deng, W.H. Li. Variable stiffness and damping suspension system for train. Proc. SPIE 9057, Active and Passive Smart Structures and Integrated Systems 2014, 90570P (9 March 2014). DOI: $10.1117 / 12.2045023$.

[19] H.R. O'Neill and G.D. Wale. Semi-active suspension improves rail vehicle ride. Computing \& Control Engineering Journal, 1994, 5(4), pp. 183-188. DOI: 10.1049/cce: 19940404.

[20] K.D. Weiss, J.D. Carlson and D.A. Nixon. Viscoelastic Properties of Magneto- and ElectroRheological Fluids. Journal of Intelligent Material Systems and Structures, 1994, 5(6), pp. 772775. DOI: $10.1177 / 1045389 X 9400500607$. 
[21] O. Ashour, C.A. Rogers and W. Kordonsky. Magnetorheological fluids: materials, characterization, and devices. Journal of Intelligent Material Systems and Structures, 1996, 7(2), pp. 123-130. DOI: 10.1177/1045389X9600700201.

[22] N.D. Sims, R. Stanway, D.J. Peel, et al. Controllable viscous damping: an experimental study of an electrorheological long-stroke damper under proportional feedback control. Smart Materials and Structures, 1999, 8(5), pp. 601-615. DOI: 10.1088/0964-1726/8/5/311.

[23] W.H. Liao and D.H. Wang. Semi-active Vibration Control of Train Suspension Systems via Magnetorheological Dampers. Journal of Intelligent Material Systems and Structures, 2003, 14(3), pp. 161-172. DOI: 10.1177/104538903033283.

[24] D.H. Wang and W.H. Liao. Semi-active suspension systems for railway vehicles using magnetorheological dampers. Part I: System integration and modelling. Vehicle System Dynamics, 2009, 47(11), pp. 1305-1325. DOI: 10.1080/00423110802538328.

[25] D.H. Wang and W.H. Liao. Semi-active suspension systems for railway vehicles using magnetorheological dampers. Part II: simulation and analysis. Vehicle Systems Dynamics, 2009, 47(12), pp. 1439-1471. DOI: 10.1080/00423110802538336.

[26] L.H. Zong, X.L. Gong, S.H. Xuan, et al. Semi-active Ho control of high-speed railway vehicle suspension with magnetorheological dampers. Vehicle System Dynamics, 2013, 51(5), pp. 600-626. DOI: $10.1080 / 00423114.2012 .758858$.

[27] S.S. Sun, H.X. Deng, W.H. Li, et al. Improving the critical speeds of high-speed trains using magnetorheological technology. Smart Materials and Structures, 2013, 22(11), pp. 1-14. DOI:10.1088/0964-1726/22/11/115012.

[28] Y.J. Shin, W.H. You, H.M. Hur, et al. Semi-active control to reduce car body vibration of railway vehicle by using scaled roller rig. Journal of Mechanical Science and Technology, 2012, 26(11), pp. 3423-3431. DOI: 10.1007/s12206-012-0861-1.

[29] H.C. Kim, Y.J. Shin, W.H. You, K. C. Jung, J. S. Oh, S. B. Choi. A ride quality evaluation of a semi-active railway vehicle suspension system with MR damper: Railway field tests. Proceedings of the Institution of Mechanical Engineers, Part F: Journal of Rail and Rapid Transit, 2016, 231(3), pp. 306-316. DOI: 10.1177/0954409716629706.

[30] J.S. Oh, Y.J. Shin, H.W. Koo, H. C. Kim, J. Park, S. B. Choi. Vibration control of a semi-active railway vehicle suspension with magneto-rheological dampers. Advances in Mechanical Engineering, 2016, 8(4), pp. 1-13. DOI: 10.1177/1687814016643638.

[31] G.S. Gao and S.P. Yang. Semi-active Control Performance of Railway Vehicle Suspension Featuring Magnetorheological Dampers. 2006 1ST IEEE Conference on Industrial Electronics and Applications. DOI: 10.1109/ICIEA.2006.257097.

[32] M.R. Chi, W.H. Zhang, J. Zeng, et al. Vibrant response characteristic of railway vehicle (in Chinese). Journal of Traffic and Transportation Engineering, 2007, 7(5), pp. 6-11.

[33] H. Claus and W. Schiehlen. Modelling and simulation of railway bogie structural vibrations. Vehicle System Dynamics, 1998, 29(s1), pp. 538-552. DOI: 10.1080/00423119808969585.

[34] A. Jaschinski, H. Chollet, S.D. Iwnicki, et al. The application of roller rigs to railway vehicle 
dynamics. Vehicle System Dynamics, 1999, 31, pp. 345-392. DOI: 10.1076/vesd.31.5.345.8360.

[35] Y.J. Shin, W.H. You, H.M. Hur, et al. Semi-active control to reduce carbody vibration of railway vehicle by using scaled roller rig. Journal of Mechanical Science and Technology, 2012, 26(11), pp. 3423-3431. DOI: 10.1007/s12206-012-0861-1.

[36] W.H. Li, X.Z. Zhang and H. Du. Magnetorheological elastomers and their applications. Advances in Elastomers, 2013, 11, pp: 357-374. DOI: 10.1007/978-3-642-20925-3_12.

[37] S.S. Sun, J. Yang, W.H. Li, et al. Development of an isolator working with magnetorheological elastomers and fluids. Mechanical Systems and Signal Processing, 2017, 83, pp. 371-384. DOI: 10.1016/j.ymssp.2016.06.020.

[38] A. Boczkowska, S. F. Awietjan, S. Pietrzko, et al. Mechanical properties of magnetorheological elastomers under shear deformation. Composites Part B: Engineering, 2012, 43(2), pp. 636-640. DOI:10.1016/j.compositesb.2011.08.026.

[39] Y.C. Li, J.C. Li, W.H. Li, et al. Development and characterization of a magnetorheological elastomer based adaptive seismic isolator. Smart Materials and Structures, 2013, 22(3), pp. 1-12. DOI:10.1088/0964-1726/22/3/035005.

[40] S.S. Sun, J. Yang, W.H. Li, et al. An innovative MRE absorber with double natural frequencies for wide frequency bandwidth vibration absorption. Smart Materials and Structures, 2016, 25(5), pp. 1-10. DOI: $10.1088 / 0964-1726 / 25 / 5 / 055035$.

[41] J. Yang, S.S. Sun, J.Y. Chi, et al. Development and evaluation of an MRE-based absorber with two individually controllable natural frequencies. Smart Materials and Structures, 2018, 27(9), pp.

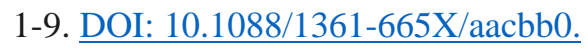

[42] P. Li, G.M. Kamath, and N.M. Wereley. Analysis and testing of a linear stroke magnetorheological damper. AIAA/ASME/AHS Adaptive Structures Forum, 1998, CP9803 (4), pp. 2841-2856. DOI: 10.2514/6.1998-2040.

[43] Z.K. Laka. Dynamic stiffness and damping prediction on rubber material parts, FEA and experimental correlation. Doctoral Thesis, 2017, Lea Artibai Ikastetxea S. Coop. and London Metropolitan University.

[44] Y.C. Li, J.C. Li, W.H. Li, et al. A state-of-the-art review on magnetorheological elastomer devices. Smart Materials and Structures, 2014, 23(12), pp. 1-12. DOI: 10.1088/0964$\underline{1726 / 23 / 12 / 123001 .}$

[45] G. Yang, B.F. Spencer Jr, J.D. Carlson, et al. Large-scale MR fluid dampers: modeling and dynamic performance considerations. Engineering Structures, 2002, 24(3), pp.309-323. DOI: $\underline{10.1016 / S 0141-0296(01) 00097-9 .}$

[46] S.A. Khan, A. Suresh and N.S. Ramaiah. Principles, characteristics and applications of magneto rheological fluid damper in flow and shear mode. Procedia Materials Science, 2014, 6, pp. 15471556. DOI: 10. 1016/j.mspro.2014.07.136.

[47] M.Y. Salloom and Z. Samad. Finite element modeling and simulation of proposed design magneto-rheological valve. The International Journal of Advanced Manufacturing Technology, 2011, 54(5-8), pp. 421-429. DOI: 10.1007/s00170-010-2963-1. 
[48] S. Yarra, F. Gordaninejad, M. Behrooz, et al. Performance of a large-scale magnetorheological elastomer-based vibration isolator for highway bridges. Journal of Intelligent Material Systems and Structures, 2018, 29(20), pp.3890-3901. DOI: 10.1177/1045389X18799493.

\section{Appendix}

A. Design and simulation of the VS-MRE isolator

The relationship between the storage modulus, loss modulus of the MRE material and the magnetic flux density (B) is shown in Figure A1. It can be seen that as the magnetic flux density increases, the storage modulus and loss modulus of the MRE material also increases.

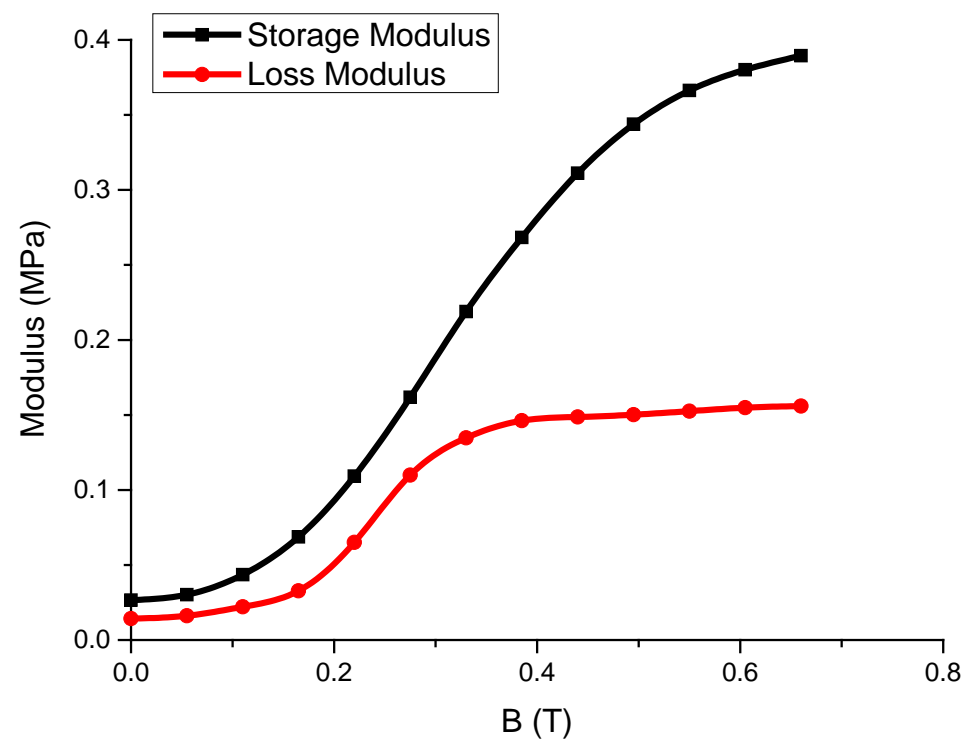

Figure A1. The relationship between the storage modulus, loss modulus of the MRE material and the magnetic flux density.

The magnetic field simulation results of the MRE isolator are shown in Figure A2 and Table A1. It shows that as the current increases, the magnetic flux density of the MRE layers also increase. 


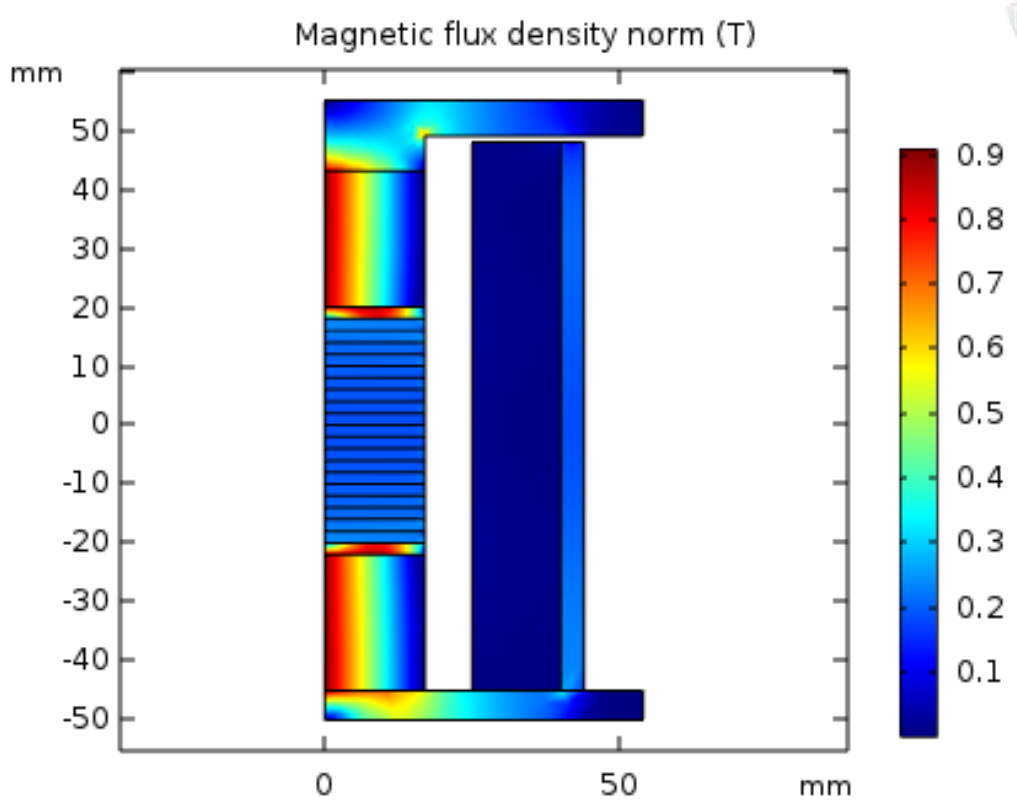

$\square$

(a)

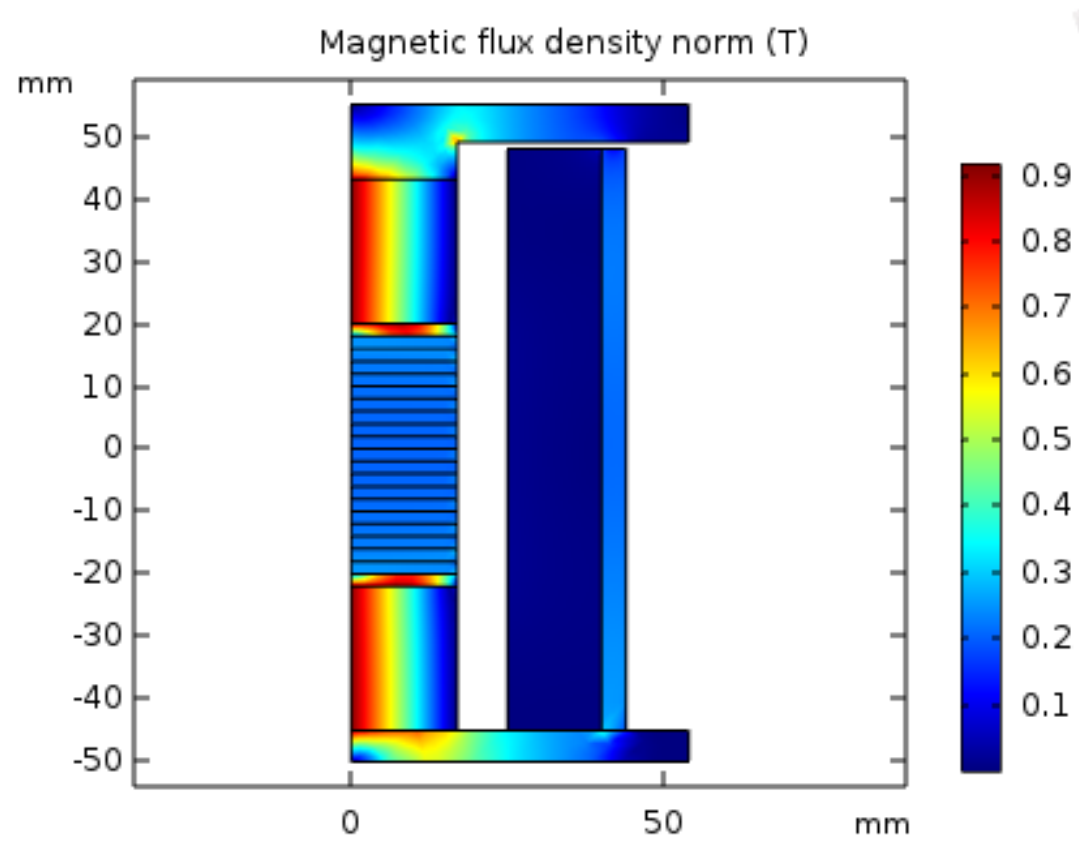

(b) 


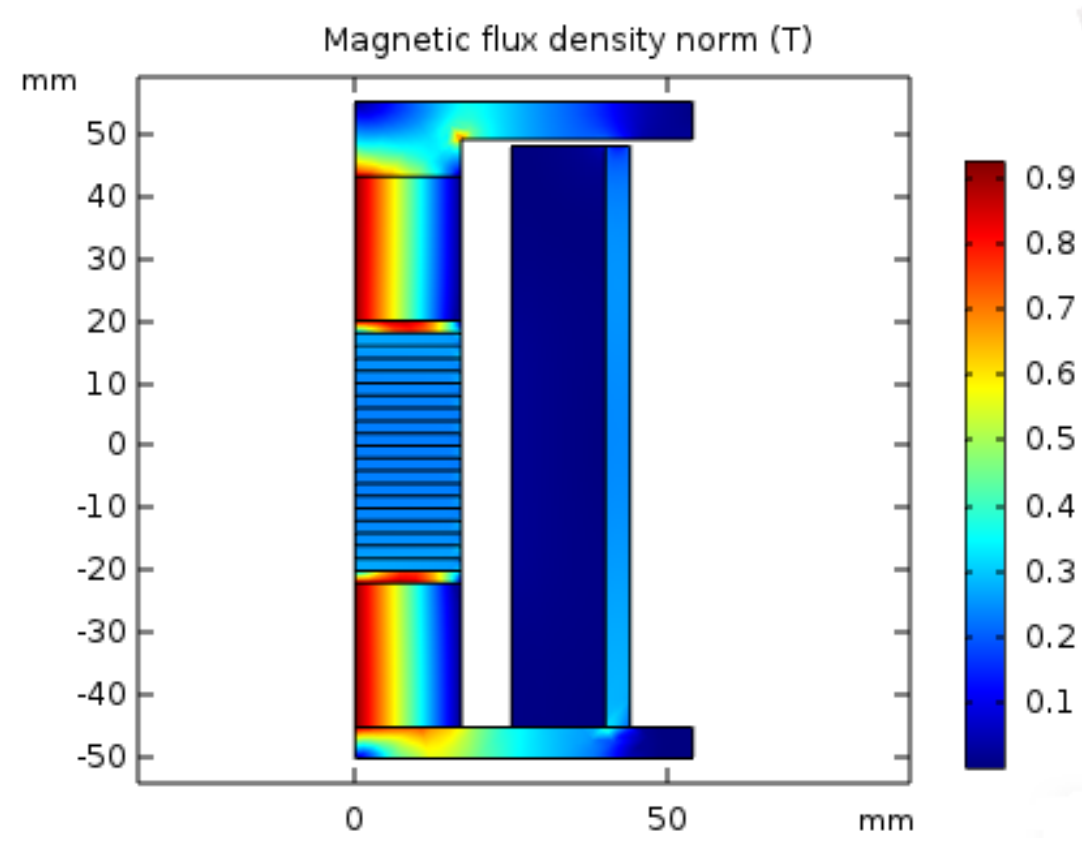

(c)

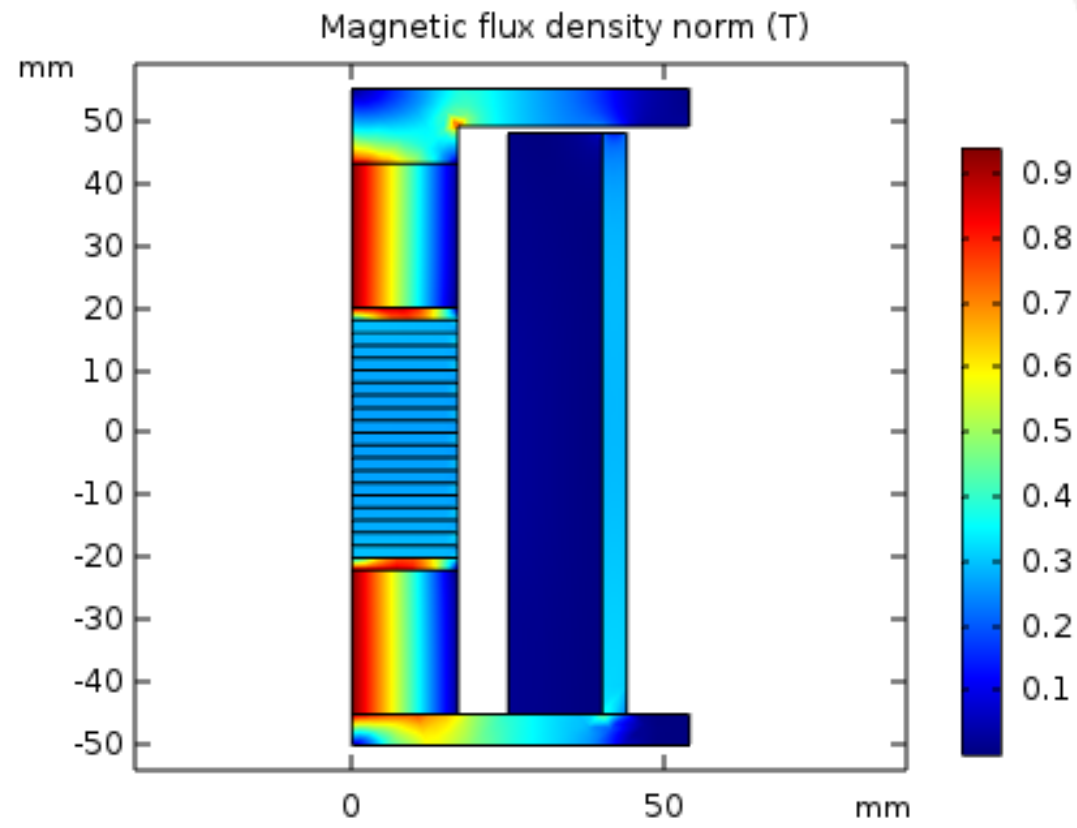

(d)

Figure A2. Magnetic flux density of the VS-MRE isolator under different currents: (a) 0 A; (b) 1 A; (c) 2 A; (d) 3 A.

Table A1. The magnetic field strength of VS-MRE isolator under different currents.

\begin{tabular}{ccccc}
\hline$I_{S}(\mathrm{~A})$ & 0 & 1 & 2 & 3 \\
\hline $\mathrm{B}(\mathrm{T})$ & 0.19 & 0.22 & 0.25 & 0.28 \\
\hline
\end{tabular}

B. Design and simulation of the VD-MR damper

The relationship between the shear yield strength $\left(\tau_{y}\right)$ of the MR fluid and the magnetic flux density (B) is shown in Figure A3. It can be seen that as the strength of the magnetic field increases, the shear yield strength of the MR fluid also increases. 


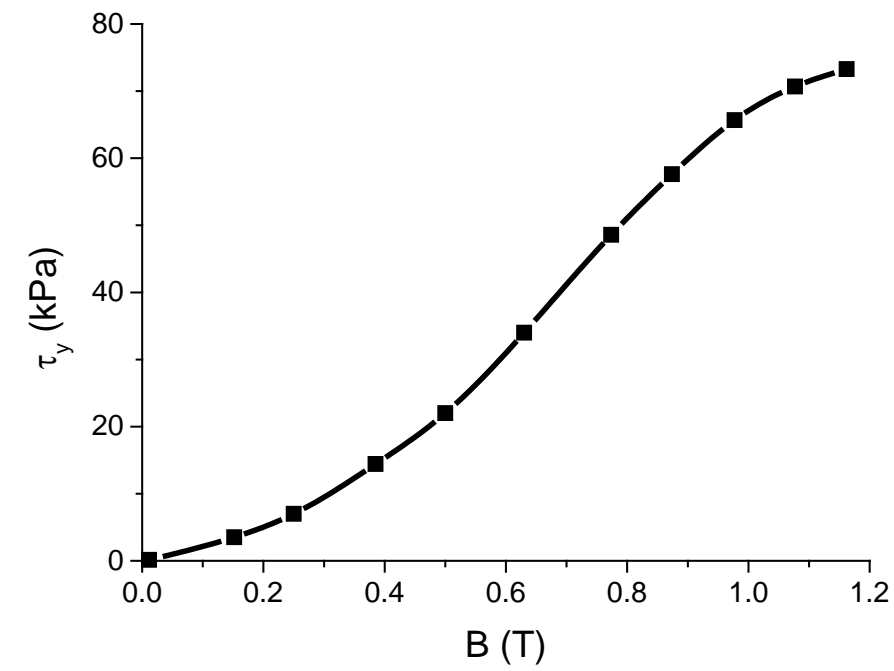

Figure A3. The relationship between the shear yield strength of the MR fluid and the magnetic field density.

The simulation analysis of the magnetic field of the VD-MR damper under different currents is conducted using COMSOL software and the results are shown in Figure A4. The magnetic flux density under different currents is shown in the Table A2.

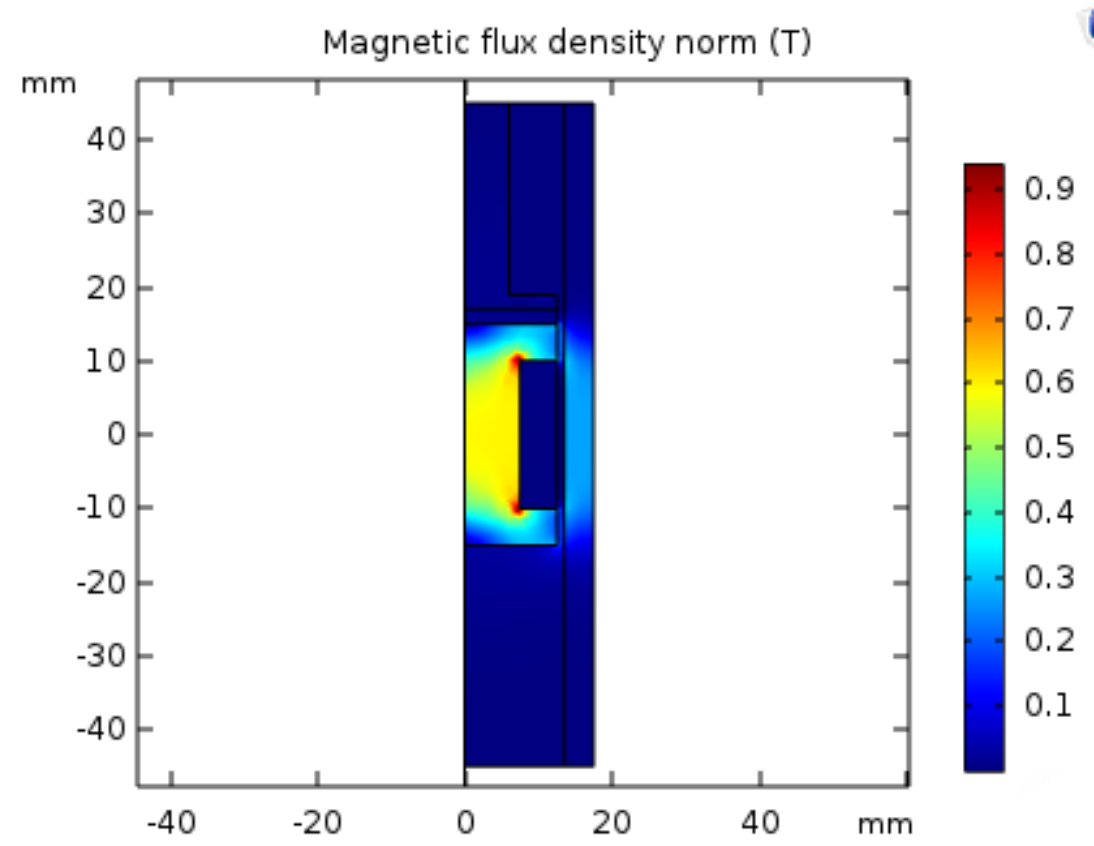

(a) 


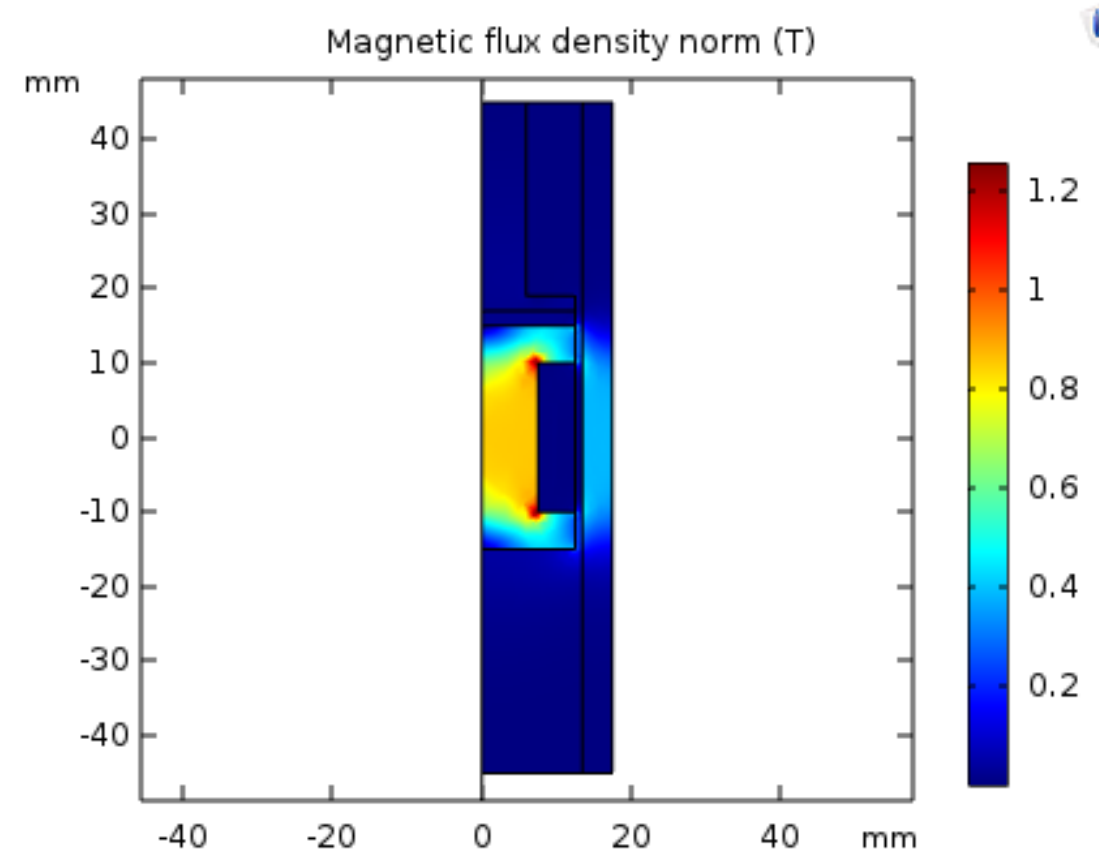

(b)

Figure A4. Magnetic flux density of the VD-MR damper under different currents: (a) 1 A; (b) 2 A.

Table A2. The magnetic flux density of the VD-MR damper under different currents.

\begin{tabular}{ccc}
\hline$I_{d}(\mathrm{~A})$ & 1 & 2 \\
\hline $\mathrm{B}(\mathrm{T})$ & 0.17 & 0.25 \\
\hline
\end{tabular}

